\title{
LA ORDEN QUE PROHIBIÓ INTERPRETAR OBRAS CLÁSICAS A LAS ORQUESTAS DE JAZZ Y DE BAILE EN LOS PRIMEROS AÑOS DEL FRANQUISMO
}

\section{THE ORDER THAT PROHIBITED JAZZ AND DANCE ORCHESTRAS FROM PERFORMING CLASSICAL WORKS IN THE EARLY YEARS OF THE FRANCO DICTATORSHIP}

\author{
Fernando Centenera Sánchez-Seco ${ }^{1}$
}

\section{RESUMEN}

En 1939 el final de la guerra civil española dio paso a una dictadura con un sistema de censura que afectaría de lleno a la parcela musical. Una de las manifestaciones más representativas fue una Orden del Sindicato Nacional del Espectáculo publicada en 1942, que prohibía interpretar obras clásicas a las orquestas de jazz y de baile. El objetivo de este trabajo es analizar esta disposición desde un punto de vista normativo. Para ello se abordan aspectos relativos a su publicación, publicidad, lenguaje o interpretación. También se considera la competencia para llevar a cabo la censura que establecía la orden, así como su puesta en práctica. En relación a esta última cuestión se tratan los cumplimientos e incumplimientos, los temas censurados y la gestión de la vaguedad lingüística de la norma. Metodológicamente, el estudio se desarrolla a partir de documentación de archivos y normativa del momento. La perspectiva que se adopta es analítica y crítica. Los resultados obtenidos muestran numerosos fracasos en los aspectos señalados anteriormente, que demuestran un desprecio manifiesto hacia las normas. Del mismo modo, se constatan importantes descoordinaciones internas y también, en parte debido a los problemas formales diagnosticados, una puesta en práctica deficiente en numerosas ocasiones.

Palabras clave. Censura, franquismo, jazz, música clásica, Sindicato Nacional del Espectáculo.

\begin{abstract}
The end of the Spanish civil war in 1939 led to a dictatorship with a system of censorship that would affect the entire musical sphere. One of its most characteristic embodiments was an Order published by the National Performing Arts Syndicate in 1942, which prohibited jazz and dance orchestras from performing classical works. This study examines this provision from a normative perspective. To that end, it considers aspects related to its publication, dissemination, language and interpretation. It also examines the authority to carry out the censorship that the order established, and its implementation. Compliance and non-compliance, the pieces censored and how the linguistic vagueness of the regulation was addressed are discussed in relation to the latter question. In methodological terms, the study is based on archive documentation and contemporary regulations. The perspective adopted is analytical and

\footnotetext{
${ }^{1}$ Facultad de Derecho. Universidad de Alcalá - Espanha. ORCID: https://orcid.org/0000-0001-9435-7008 E-mail: fernando.centenera@uah.es
} 
critical. The results highlight numerous failures in the aspects mentioned above, which demonstrate a blatant disregard for the rules. Likewise, a significant absence of internal coordination is apparent, as well as shortcomings in its implementation on numerous occasions, which were partly due to the formal problems diagnosed.

Keywords: Censorship, classical music, Francoism, jazz, National Performing Arts Syndicate.

\section{INTRODUCCIÓN}

"La música de baile es la forma más antigua de expresión musical y todo el mundo sabe que muchos de los mejores trabajos de los clásicos fueron escritos para bailes de su época". Con estas palabras Valcárcel (1935a, p. 16; 1935b, p. 13) rebatía a mediados de la década de los treinta del siglo pasado a quienes rechazaban al jazz, por ser considerado inferior desde el punto de vista musical. Meses después, ya en la antesala de la guerra civil, la conexión entre la música clásica y la moderna se ponía de manifiesto por parte de Ramos Echapare (1936, p. 14), que concebía al jazz como una ramificación de la primera. Eran aportaciones contextualizadas en debates intelectuales que traspasaban fronteras, como así lo certifica la obra de Adorno (2011, p. 831), donde el jazz quedaba relegado a un lugar inferior, frente a lo que el filósofo denominaba "música artística" de Brahms o Strauss. Sin embargo, el devenir de las circunstancias en España pronto acabaría con aquel espacio de reflexión. El golpe de Estado conduciría al estallido del conflicto bélico y, con él, a la politización musical acompasada con los acontecimientos.

No era algo nuevo. El 20 de julio de 1937, la entrega correspondiente de El Observador del Reich incluía un texto titulado El futuro del Arte alemán, que informaba de varios eventos nazis desarrollados en el panorama artístico. En él las alabanzas a las "sinfonías clásicas alemanas" y a "las canciones de Beethoven a la alegría", se conjugaban con el relato de los jerarcas nazis sobre el arte. Frente a ello, se daba también cuenta de la dureza con la que se había emprendido la condena del "arte ambiguo", considerado de una época pasada, ya muerta, que no tendría lugar en Alemania. El organicismo se esparcía así entre aquellas letras reivindicando el "derecho a la vida del pueblo", donde el arte, lejano de las modas, se erigía como "supremo valor vital" de aquel. Eran manifestaciones que debieron tener lugar en la Gran Exposición de Arte alemán de 1937, celebrada coetáneamente a la dedicada al Arte Degenerado (“El futuro del Arte alemán...", 1937). Pocos días después de que aparecieran, ya en plena guerra civil, el bando sublevado emitía la Circular 52 (1937), que restringía las emisiones de varios tipos de música moderna, al tiempo que solicitaba incrementar las dedicadas al vals. La 
misma disposición establecía además la conveniencia de radiar cotidianamente obras clásicas que fueran entendibles para el público. Estas últimas se tomaron de inmediato como estandarte musical, así lo atestiguan los pedidos urgentes de discos procedentes de la Delegación del Estado para Prensa y Propaganda, que solicitaba obras de Wagner, Beethoven, Chopin, Brahms, Schubert o Rimsky-Korsakov. La documentación es muy clara en lo que respecta a los objetivos propagandísticos que se pretendían con aquellas grabaciones. Precisamente, a razón de ello, se requería un descuento especial en las compras, además del establecido reglamentariamente, con el añadido, cargado de intenciones, de que aquel fuera acorde al patriotismo que se tuviera (Nota dirigida al Bazar Electra, 1937).

El final de la guerra civil dio paso a una dictadura que impregnaría toda su oficialidad con la música clásica, utilizada hasta la saciedad con fines políticos en actos y efemérides. Como modelo, también en esta ocasión, Alemania, junto con su aversión hacia las potencias Aliadas en el contexto de la II Guerra Mundial, pues aquel rechazo también sería compartido por el régimen, encontrando cumplido reflejo en sus medidas. Los medios daban cuenta de ello, así lo constatan espacios como el firmado por Contreras para Radio Madrid, en el cual se reivindicaba el papel de la radio como instrumento de propaganda política, viéndose en Alemania la referencia a seguir, donde la música romántica y la clásica tenían un papel principal, frente a la "industrial y populachera" (Contreras, 1942). La intención era elevar el arte musical, que había quedado "un poco abotargado por la influencia de la música americana tan peligrosa", según aseveraba el sacerdote Otaño en sus críticas musicales (Contreras, 1942). En aquello se empeñarían numerosas disposiciones procedentes de la Vicesecretaría de Educación Popular, un órgano de la Falange, del cual dependía la Delegación Nacional de Propaganda. Es el caso de la Circular 96 (1942), que apareció a propósito del "día del Caudillo", el 1 de octubre. Para la fecha se solicitaba la emisión de marchas de Wagner, Meyerbeer, Verdi, Beethoven o Schubert, apuntándose además que se podían completar los programas con temas como "la obertura de Tannhäuser" o la "Cabalgata de las Valkirias". Días después, la Circular 103 (1942), emitida para el "9ªniversario del acto fundacional de la Falange", establecía lo siguiente: "La parte musical de las emisiones estará compuesta por obras de Bach, Beethoven, Wagner o Mozart, incluyéndose de ser posible la Novena Sinfonía con coros del compositor mencionado en segundo lugar".

Atendiendo a manifestaciones como las anteriores, podría decirse que aquel pretendido "esteticismo de la política" se había programado con un objetivo claro: proporcionar un aura de gravedad y heroicidad (Selva, 2009, p. 64) para el régimen. No es gratuita la observación de que las piezas citadas aportan una intensidad que trasmite sensaciones de energía o valor (Muñiz 
Velázquez, 1998, p. 347); lo cual nos lleva pensar que estamos ante el imperativo de mantener vivo el recuerdo de la victoria del bando sublevado en la reciente guerra civil. Conviene reseñar que en la propaganda e ideario del régimen las obras de Wagner habían sido pensadas para cantar "hazañas de héroes y semidioses" (Tercero, 1942, p. 26) o que, según Giménez Caballero (2009, p. 201), el músico alemán había pretendido corregir la individualidad de la ópera, tratando de acercarla a los "misterios épicos y legendarios". Con todo ello, el colosalismo arquitectónico parecía cobrar carta de naturaleza en lo musical, aunque corregido en cuanto al significado, si se compara con las experiencias del fascismo y el nazismo. El nuevo régimen se vertebraba en torno al catolicismo que, interesada y forzadamente, lo identificaría con Occidente $^{2}$, esparciendo tal impronta por doquier. Son muy significativas las manifestaciones propagandísticas que recogeremos en este estudio, en las cuales la música clásica aparece como fruto de la religiosidad de Occidente, de la cual el régimen se había erigido en el más ferviente defensor.

Frente a tal planteamiento, puede imaginarse la reacción ante la práctica de interpretar la música que se había tomado por insignia con ritmos modernos. En lo normativo, la respuesta, reaccionaria, encontró su manifestación más representativa en una Orden del Sindicato Nacional del Espectáculo que apareció a mediados de 1942, con la cual se prohibía la interpretación de música clásica por orquestas de jazz y de baile. La norma se ha considerado en numerosos estudios, y junto a ella, en ocasiones también manifestaciones que la reivindicaron y saludaron con entusiasmo ${ }^{3}$. Con este trabajo pretendemos ofrecer un análisis de la disposición desde una perspectiva principalmente normativa que, a nuestro modo de ver, ofrece la oportunidad de presentar aportaciones novedosas ${ }^{4}$. A la hora de llevar a cabo este desarrollo hemos optado por un esquema que repara en aspectos como la publicación, la publicidad, cuestiones lingüísticas de la norma y determinados aspectos relativos a la competencia y aplicación de la censura. También ofrecemos un acercamiento al cumplimiento e incumplimiento de la orden, ejemplos de temas que quedaron censurados, los posibles recursos utilizados para ello y experiencias sobre determinados casos dudosos. Varias de las referencias que utilizaremos ya se han considerado en algunos estudios. Otras, al menos hasta

\footnotetext{
${ }^{2}$ Planteamos este argumento a partir de los datos que ofrece Cirili, 1977, pp. 18-45.

${ }^{3}$ Puede verse García, [2013], pp. 32, 33; Iglesias, 2010, pp. 126, 127; Iglesias, 2017, pp. 117, 118; Moreda Rodríguez, 2017, p. 115.

${ }^{4}$ Recientemente hemos llevado a cabo otros trabajos sobre algunas disposiciones del régimen en materia musical, donde presentamos análisis normativos: Centenera Sánchez-Seco, 2019, pp. 65-96; Centenera Sánchez-Seco, 2020, pp. 1-51. Este estudio contribuye a confirmar problemáticas ya diagnosticadas en aquellos, pero también a poner de manifiesto otras, que amplían el conocimiento sobre la censura llevada a cabo por el régimen.
} 
donde llegamos a conocer, aparecen por primera vez en este trabajo ${ }^{5}$. Se trata de documentación que forma parte de los fondos del Archivo General de la Administración (en adelante AGA), la Biblioteca Nacional de España (en adelante BNE), la Biblioteca de Comunicación y Hemeroteca General de la Universidad Autónoma de Barcelona y la Biblioteca Universitaria de la Universidad de Castilla-La Mancha (en adelante BU.UCLM) ${ }^{6}$.

\section{PUBLICACIÓN, PUBLICIDAD Y PROPAGANDA}

El 26 de enero de 1940 el Boletín Oficial del Estado publicaba una ley con la cual se reconocía a la Organización Sindical del partido como la única, manifestándose al tiempo los principios que la inspirarían: "Unidad, Totalidad y Jerarquía" ("Ley de 26 de enero de 1940 [...]", 1940, parte expositiva y artículo 1). Aquel planteamiento, marcadamente excluyente y con vocación de control y disciplina, se vertebraría un año y medio después, también por vía normativa, en torno a veinticuatro sindicatos nacionales. Entre ellos, el Sindicato Nacional del Espectáculo (“Ley de 23 de junio de 1941 [...]”, 1941, parte expositiva y artículo 1), que pocos meses después sería reconocido como "corporación de Derecho público con personalidad jurídica", integrándose también desde entonces en él la Sociedad General de Autores de España (“Decreto de 19 de febrero de 1942 [...]", 1942, artículos 1 y 5.). Corría por entonces el año 1942, y en su ecuador el Boletín del Sindicato Nacional del Espectáculo publicaría la orden que nos interesa, firmada por Francisco Casares, como jefe nacional del Sindicato Nacional del Espectáculo. La disposición apareció en los siguientes términos:

"Por constituir un caso de gravísimas consecuencias y efecto deplorable, en orden artístico, la insolente costumbre practicada por las orquestinas de baile de interpretar adaptaciones de obras clásicas originales de compositores inmortales, al género de «jazz», además de representar esta práctica un descarado y vergonzoso atentado a la admiración y respeto que aquellas gloriosas páginas musicales merecen, pongo en tu conocimiento su cumplimiento inmediato y de un modo tajante y absoluto la siguiente

\footnotetext{
${ }^{5}$ Tanto en los títulos de las referencias, como en los textos transcritos de las mismas, hemos corregido el uso de tildes, puntuación, faltas de ortografía y erratas. En este último caso proponemos entre corchetes lo que, según nuestro criterio, debería entenderse. Utilizamos el mismo recurso ocasionalmente en la cita de algunos documentos, cuando, por ejemplo, no hay títulos en ellos, o resultan incompletos a nuestro criterio. Por otra parte, con el fin de que se puedan identificar correctamente oficios, notas de servicio interior, informes de Delegaciones Provinciales y cuadernos de emisiones radiofónicas (estos últimos cuando se nombran en un sentido general), hemos incluido en su cita en el texto, además del año, como en el resto de casos, el día y el mes (o semana/s de mes, en su caso).

${ }^{6}$ En el último y antepenúltimo caso, a propósito de referencias sonoras.
} 


\section{Orden}

«A partir del día de hoy, queda terminantemente prohibido por esta Jefatura Nacional la interpretación por orquestas de «jazz» y de baile en general de las obras de repertorio clásico. Los contraventores de esta Orden se atendrán a las consecuencias que su grave responsabilidad les produzca.

Desde el momento en que recibas el presente oficio, harás que ese Sindicato de tu mando adopte una actitud extremadamente vigilante y deberás comunicar telegráficamente a esta Jefatura la más pequeña infracción que en este sentido se produzca».

Por Dios, España y su Revolución Nacional-Sindicalista.

Madrid, 25 de agosto de 1942.- El jefe nacional, Francisco Casares.- V. ${ }^{\circ}$ B. ${ }^{\circ} \mathrm{El}$ vicesecretario de ordenación Económica, Miguel M. Troncoso." (“Grupo de Música. Orden", 1942, p. 17).

La orden, por tanto, se publicó en el Boletín del Sindicato Nacional del Espectáculo, pero cabría entender que probablemente ello no fue suficiente para hacer llegar la prohibición a todas sus audiencias; las publicaciones sindicales no tenían una repercusión representativa en el sector al que iban dirigidas (López Gallegos, 2003, p. 176). No obstante, debe señalarse que además de la publicación se recurrió a la publicidad en diferentes medios de comunicación. En base a los documentos consultados, cabe señalar que probablemente, las iniciativas en este segundo sentido procedieron de los sindicatos locales, encargados de vigilar el cumplimiento, al menos en teoría ${ }^{7}$. Aquellos debieron también informar de la orden a empresas, orquestas de baile y delegaciones comarcales (Valladolid. Informe mensual [...], 1942, p. 39).

La publicidad en la prensa escrita aparecería en noticias de varios periódicos. Así, por ejemplo, en La Vanguardia Española, bajo el título "Velando por la Pureza de la Música" (1942, p. 3), podía leerse el siguiente texto:

\footnotetext{
"Recientemente, y por el Sindicato Nacional del Espectáculo, ha sido puesta en vigor una orden, por la que se prohíbe a las orquestas de bailes interpretar adaptaciones al general de "jazz" de las obras de repertorio clásico que se deben a compositores inmortales.

En virtud de esta disposición, se pone término, de modo tajante, a tan deplorable costumbre, últimamente observada con harta frecuencia en salas de fiesta, hoteles cafés, etc., lo que, sobre representar una verdadera irreverencia desde el punto de vista artístico, por las razones antes citadas, constituía motivo de graves y trascendentales efectos, que tan directamente aduleran [entendemos 'adulteran'] la pureza del ambiente musical de España."
}

\footnotetext{
${ }^{7}$ Así lo hemos de entender, si tenemos en cuenta el siguiente documento, donde se hace referencia a la publicación en prensa: "Valencia. Parte de actividades [...]", 1942, p. 38.
} 
El análisis detenido de la noticia demuestra que no se trataba de una comunicación fiel al contenido de la orden. Como sabemos, esta última prohibía que las orquestas de jazz y de baile interpretaran música clásica. De este modo, cabría entender que la prohibición no alcanzaba únicamente a los temas en los que se interpretase música clásica con jazz, sino también a aquellos en los que se hicieran adaptaciones con otros ritmos bailables (pensemos, por ejemplo, en el tango). En todo caso, cabría apuntar que la circunstancia expuesta probablemente trajese causa de la redacción de la disposición que, como veremos más adelante, no fue precisamente acertada.

La prohibición se anunciaría también en otros periódicos, como $P R O A$, un diario de la Falange en León (Cifra, 1942, p. 1), o Falange de Las Palmas de Gran Canaria. En este último podía leerse lo siguiente:

“A partir del día de hoy queda terminantemente prohibido por la Jefatura Nacional
del Sindicato del Espectáculo, la interpretación por orquestas de «jazz» y de baile
en general, de Obras de repertorio clásico. Los contraventores de esta orden se
atendrán a las consecuencias que la grave responsabilidad les produzca. El Jefe
de la Sección de Músicos del Sindicato Local del Espectáculo vigilará el más
exacto cumplimiento a esta orden" (“Sindicato Local del Espectáculo [...]”, 1942,
p. 2).

Junto con la noticia de la prohibición, la prensa y la radio también recogieron opiniones afines a aquella, planteadas en tono propagandístico. Se trata de textos caracterizados por manifestaciones racistas y bélicas (Tercero, 1942, p. 26 ; Prados López, 19429), y con frecuentes alusiones a la animalización de los aspectos musicales del jazz (Tercero, 1942, p. 26) ${ }^{10}$, su relación con el capitalismo, inmoralidad, o carácter enfermizo (Prados López, 1942) ${ }^{11}$. Frente a ello, la música clásica aparece como la antítesis, en íntima conexión con la religión y lo espiritual (Prados López, 1942 ${ }^{12}$; Llabrés, $1942^{13}$ ). Tampoco faltaron dosis de comicidad en

\footnotetext{
${ }^{8}$ Alude a la música y danzas "negroides", y con ocasión del tema que nos ocupa se refiere a "un nuevo combate contra otro adversario".

${ }^{9}$ Donde la "música de negros" se presenta como algo brutal.

${ }^{10}$ Texto en el que puede leerse "danzas propias de orangutanes".

${ }^{11}$ Donde se considera que las prácticas prohibidas "adulteran la pureza del ambiente musical de España", o que la "música de negros" es una decadencia repugnante e inmoral. La referencia relaciona además la música o el arte moderno con lo enfermo o sucio, o bien con lo que da lugar a ello, presenta dichos registros como "intromisiones malsanas, venenosas, perjudiciales para la juventud", y considera que la regulación que nos ocupa es una manifestación de higiene moral en lo artístico.

${ }^{12}$ El texto sitúa a la música clásica en el estadio de lo "selecto y elevado", señalando lo siguiente: "al menos habremos logrado que aquellos trozos de arte que el sueño de unos privilegiados nos legaron como un tesoro sean escuchados con la unción, con el respeto y la religiosidad con que fueron concebidos e inspirados".

${ }^{13}$ En la referencia puede leerse lo siguiente: "Cada cosa en su punto. La música de Chopin para deleite del espíritu y lo semas [ entendemos 'demás'] para amalgamar las danzas absurdas y el humo del tabaco rubio".
} 
los comentarios, como puede verse en el siguiente texto, que se publicaba a propósito de la aparición de la orden:

\footnotetext{
"Yo tengo un amigo que se ha quedado viudo hace diez días y anoche me lo encontré en la calle y me dijo que se iba al cabaret. La verdad, me pareció demasiado pronto, por muchas ganas que tuviera y así se lo dije:

-Chico, yo creo que... Vamos, me parece a mí...Yo en tu caso esperaría por lo menos un mes...Puede verte alguien y van a criticar tu manera de guardar el luto...

Y entonces él, con una cara muy triste y con un conato de lágrimas al borde de los ojos me contesto:

-No, hombre, no. ¡Si yo conservo vivo y coleando mi dolor! ¡Si yo respeto mi luto! Precisamente si voy al cabaret es porque allí tocan música negra." (Llabrés, 1942).
}

Manifestaciones como las consideradas no fueron exclusivas del momento en el que apareció la norma. La propaganda en pro de la música clásica y contraria a la moderna se prolongaría en el tiempo, en ocasiones con un nivel de gravedad parecido. Un año y algunos meses después se seguiría aludiendo al carácter criminal del jazz, considerándose crímenes y sacrilegios artísticos las adaptaciones clásicas en aquel registro (Laguna Azorín, 1943). Otras veces, el relato se presentaría más relajado en lo que respecta a las formas, aunque sin que por ello se olvidase la ironía o la burla ${ }^{14}$.

En base a lo anterior, cabría pensar que la información proporcionada por los medios sobre la prohibición habría llegado a las audiencias de la norma que, si tenemos en cuenta lo dicho anteriormente, probablemente no accedió a aquella publicación oficial de escasa repercusión. Sin embargo, como veremos más adelante no aconteció de tal modo; este sistema de publicación y publicidad ni siquiera alcanzaría a determinados contextos en los que se desarrollaría buena parte de la censura. No obstante, cabría entender que, al menos en parte, tal circunstancia no sería propiamente un problema que trajera causa de una publicación y publicidad deficientes, sino del procedimiento llevado a cabo para implementar la censura, no precisamente acorde a los cauces normativos establecidos.

\section{LA FALTA DE CLARIDAD LINGÜÍSTICA}

\section{1. Omisiones, vaguedades manifiestas y 'sutiles' inconsistencias}

\footnotetext{
${ }^{14}$ Puede verse Sanz, 1944, que compara el vals con el fox moderno. El primero se ensalza y se contextualiza en el siglo XIX, donde se considera que la música era algo casi sagrado, en detrimento del swing, caracterizado como "frenético aceleramiento de absurdos movimientos, en desequilibrio de epilépticos danzarines".
} 
La orden que nos ocupa presenta varios aspectos que debieron suscitar incertidumbre por diversas razones. Probablemente los más evidentes sean la ausencia de una correcta tipificación, que reparase en las posibles formas de infracción y su nivel de gravedad (considerándose, por ejemplo, la cantidad de temas interpretados, los lugares de actuación, la reincidencia, etc.), así como la inexistencia de un sistema sancionatorio para los casos de incumplimiento. Recordemos que el texto se limita a reseñar la gravedad de la infracción, y que quien la llevase a cabo tendría consecuencias.

Por otra parte, el ámbito de aplicación de la orden también debió suscitar dudas. En este sentido, cabría preguntarse si la prohibición alcanzaba a la reproducción de discos y a su producción. En relación al primer contexto cabría señalar que un mes y varios días después de que entrara en vigor la orden, una nota de prensa informaría de que aquella comprendía la emisión de discos en público, incluyendo las salas de cine, tanto en los intermedios como al comienzo y final de los espectáculos ("Nota del Sindicato Nacional del Espectáculo", 1942, p. 6). Con ello, por tanto, los interrogantes quedaban resueltos, pero debe señalarse que la aclaración no debió ser suficiente para llegar a todas las audiencias de la norma, como veremos más adelante (algo que no sería de extrañar, habida cuenta del carácter puntual de la publicidad), y que, por lo demás, tampoco fue precisa a la hora de referirse a la fecha de entrada en vigor de la orden. ${ }^{15}$

Más problemática debió resultar la cuestión de si la prohibición alcanzaba a la producción de discos. Es cierto que, al menos en principio, en determinados contextos así se debió pretender. En dicho sentido se planteó una propuesta procedente de la Delegación Nacional de Propaganda, previa a la aparición de la orden (Oficio de la Delegación Nacional de Propaganda [...], 21 de mayo de 1942) ${ }^{16}$. Sin embargo, la norma no emanó finalmente de aquella, sino del Sindicato Nacional del Espectáculo; y en tal circunstancia podrían considerarse varias opciones. En base a una interpretación sociológica de la norma, cabría entender que la prohibición no alcanzaba a la producción de discos. En este sentido, debe tenerse en cuenta que con su aparición, en muchas ocasiones se aludía a actuaciones de agrupaciones musicales que

${ }^{15}$ En el anunció en cuestión se dice que la orden había entrado en vigor el 2 de septiembre. Ello probablemente se debiera a que en el mismo periódico, una noticia anterior que informaba de la disposición estaba datada en el día citado ("Velando por la pureza de la música", 1942, p. 3). Sin embargo, debe recordarse que la orden tiene la fecha de 25 de agosto de 1942. Per se, técnicamente el dato no conduce a afirmar que la entrada en vigor tuviera lugar entonces. Sin embargo, el texto de la norma resulta determinante en esta cuestión, al confirmar explícitamente que la prohibición comenzaba a partir del día señalado (recordemos que dice "A partir del día de hoy [...]").

${ }^{16}$ En este documento se propone una orden en la que se establezca "la absoluta oposición a permitir impresión o edición alguna de [entendemos 'que'] roce el prestigio musical que España merece”. Se alude al documento en Pérez Zalduondo, 2011, p. 882. 
tenían lugar en contextos tales como hoteles, salas de baile, etc. Teniéndolo en cuenta, cabría entender que la orden incidía en interpretaciones ofrecidas in situ para un público determinado. Tal planteamiento quedaría además reforzado si atendemos al añadido que apareció después de la publicación, con el cual se aclaraba que la prohibición alcanzaba a la emisión pública de discos, sin aludir a la industria discográfica. No obstante, frente a todo ello cabría señalar que el tenor literal de la norma podría dar lugar a entender que la prohibición comprendía cualquier tipo de interpretación dirigida a una audiencia, aun cuando en el momento de la ejecución aquella no estuviera presente. En tal caso, debería entenderse que las grabaciones de discos entraban dentro del veto.

Por otra parte, nos parece interesante establecer una comparación entre el texto introductorio de la orden, y el que establece la prohibición. En aquel se denuncia la costumbre de las orquestas de baile de interpretar música clásica con jazz. Sin embargo, el texto de la orden que aparece a continuación del anterior no se refiere únicamente a ello; en él se prohíbe que, tanto las orquestas de jazz como las de baile, interpretasen música clásica. La diferencia puede considerarse sutil y sin mayor relevancia, pero un análisis detenido demuestra que no es así. El texto introductorio se circunscribe a la interpretación de música clásica con jazz, pero como ya señalamos, el de la orden propiamente dicha, además de referirse a aquel ámbito, amplía la prohibición a las interpretaciones de música clásica con otros ritmos bailables, además del jazz. Debe subrayarse el detalle de que en este segundo caso se alude a orquestas de jazz y de baile.

Cabría añadir además que el texto de la orden da lugar a dos tipos de interpretación, la literal y la teleológica, que no en todo caso habrían conducido al mismo resultado. Siguiendo el tenor literal de la disposición podría entenderse, por ejemplo, que quedaba prohibido que una orquesta de baile interpretase un vals clásico, según fue compuesto originalmente. Sin embargo, una interpretación en un sentido finalista, que probablemente era la que se pretendía, no llevaría al mismo resultado. Esta última opción es la que se percibe en varios de los textos que publicitaron la orden, y también en los que incluían propaganda a propósito de aquella. Así, en el titulado Crítica de Arte, donde se considera la orden "que prohíbe terminantemente a las orquestas de baile interpretar adaptaciones al género de jazz de las obras de repertorio clásico que se deben a autores importantes" (Prados López, 1942). Lo mismo cabría decir del programa desarrollado en el espacio Eutrapelias Radiofonicas, donde podemos leer lo siguiente: "Una reciente y magnifica disposición ha prohibido que la divina música de Chopin pueda ser descuartizada a base de trompetazos, platillazos, saxofonazos y demás cacharrazos..." (Llabrés, 1942). Desde este punto de vista, que remite a una interpretación finalista de la norma, si 
retomamos el ejemplo anterior la interpretación de un vals clásico con jazz, o con otros ritmos bailables ${ }^{17}$, entraría dentro de la prohibición, pero no su ejecución por una orquesta de jazz o de baile, sin ser adaptado a los registros citados. Podría considerarse que la estructura instrumental de estas últimas agrupaciones hacía imposible que interpretasen obras clásicas. Sin embargo, los registros musicales de la época demuestran que no necesariamente tendría por qué ser así. En todo caso, ante el panorama descrito, las complicaciones en el ámbito de la aplicación normativa quedaban servidas.

\section{2. La vaguedad aparentemente inexistente: sobre la interpretación de la música prohibida}

Además de los casos anteriores, el análisis de la orden descubre otro problema de vaguedad lingüística que incide en el propio fin de la prohibición: la interpretación de música clásica con jazz u otros ritmos bailables. En un primer acercamiento, la cuestión no parece presentar complicaciones, pero un análisis detenido en la posible casuística manifiesta su calado. En principio, podrían considerarse una serie de referencias que parecen entrar dentro del núcleo de certeza de la prohibición y que, por tanto, cabría entender que quedaban prohibidas. Pensamos, por ejemplo, en Song of India de la orquesta de Tommy Dorsey (una adaptación de la obra con el mismo título de Rimsky-Korsakov); o en Charlie 's Prelude (basado en el Preludio en Mi Menor de Chopin), Beethoven Riffs on (basado en el movimiento 2 de la $7^{a}$ Sinfonía de Beethoven) o Sugar Rum Cherry (basado en la Danza del Hada de Azúcar de Tchaikowsky) del Sexteto de John Kirby ${ }^{18}$. La práctica no era exclusiva de las agrupaciones musicales extranjeras, las españolas también se recreaban en ella, como así lo prueban las siguientes referencias: Nocturno (sobre una melodía de Chopin) de Tejada y su Gran Orquesta (1939?); Ilusión y Mi última romanza (dos fox lentos, uno a partir de un tema de Chopin y otro en base a una composición de Tchaikowsky) de Rafael Medina y su Orquesta (1942); Mi único romance (un fox lento desarrollado a partir de una melodía de Tchaikowsky) de la Orquesta Plantación (1942); Fantasías, $1^{a}$ parte: a tiempo de fox / Fantasías, $2^{a}$ parte: a tiempo de fox (inspiradas en Momento musical de Schubert, Rigoletto de Verdi, Rapsodia húngara ${ }^{\circ} .^{\circ}$ de

\footnotetext{
${ }^{17}$ Las declaraciones señaladas centran la atención en el jazz, pero como hemos reseñado en el texto, la orden se refiere a las orquestas de jazz y de baile, por lo que cabría concluir que la interpretación finalista alcanzaría a ejecuciones de obras clásicas interpretadas con jazz, pero también con otros ritmos bailables.

${ }^{18}$ A la hora de elaborar esta lista nos hemos guiado por la información de la siguiente referencia, en lo que respecta a la adaptación de temas clásicos al swing: Nicholson, 2014, pp. 146, 147.
} 
Liszt, Sonata Patética de Beethoven, Nocturno de Chopin y Tannhäuser de Wagner) de José Azarola (1942).

Si bien, como adelantamos, en un principio podría entenderse que las referencias anteriores quedaban prohibidas, un análisis más detenido suscita dudas en algunos casos, y ello por diferentes razones. Así, por ejemplo, por una parte, cabría señalar que la última referencia citada recoge ejecuciones de un pianista, no de una orquesta de baile. ¿Debía, entonces, prohibirse? Recordemos que la orden se refería a orquestas de jazz y de baile. Por otra parte, tiene sentido preguntarse acerca de si el hecho de encontrar fundamento o inspiración en una obra clásica, debería considerarse también interpretación de la misma. Se trata de un análisis que podría desarrollarse en la parcela de lo cualitativo, pero también cabría estudiar la cuestión desde un punto de vista cuantitativo. A propósito de ello, convendría formular interrogantes como el siguiente: ¿podría dar lugar a la prohibición la ejecución, con música de jazz o bailable, de una simple estrofa perteneciente a una obra clásica, o de motivos de esta última presentados puntualmente?

Un análisis práctico demuestra hasta qué punto la claridad inicial se torna en incertidumbre en algunos casos. Podemos, por ejemplo, considerar el tema Bach Goes in Town, interpretado por una agrupación de Benny Goodman ${ }^{19}$. Aunque el título parece anunciar una referencia que traspasaba la línea roja de la prohibición, lo cierto es que no se trata de una interpretación de un tema clásico, sino de una referencia que aglutina un conjunto de clichés barrocos (Lambert, 2013, p. 14) que recuerdan a la música de Bach. ¿Cabría, entonces, entender que el tema entraba dentro de la prohibición? No parece que fuera así; incluso las dudas persistirían en el caso de que se apreciasen coincidencias entre algunos de aquellos clichés y otros presentes en obras clásicas. Podríamos considerar además el sorprendente solo del pianista Jess Stacy en la interpretación de Sing, Sing, Sing (With A Swing), durante el concierto ofrecido por Benny Goodman (s. d.) en el Carnegie Hall en 1938. Al parecer, al menos en parte se debió a que el músico había escuchado poco antes del concierto a Debussy (Tackley, 2012, p. 154). ¿Debería entonces prohibirse esta versión del tema?, ¿únicamente la parte del solo de piano?

Parece fuera de duda que compositores como Debussy influyeron en el panorama del jazz (aquel estaba entre los preferidos de Duke Ellington, por ejemplo); aun cuando el impresionismo que inspira su música suele aparecer encasillado en aquel bajo el esquema de métrica y armonía de los ocho compases (Adorno, 2008, pp. 99-100). Quizá podría ilustrar tal

\footnotetext{
${ }^{19}$ La Compañía Gramófono Odeón editó el tema en 1942, aunque con el título Bach va a la ciudad (Orquesta Benny Goodman, 1942).
} 
circunstancia el hecho de que, por ejemplo, Moonlight Serenade de Glenn Miller (1941?) presente ciertos movimientos que recuerdan a la parte central de Clair de Lune del autor clásico (Claude Debussy, 1942). De nuevo en casos como este, cabría renovar los interrogantes que venimos planteando.

Sin ánimo de presentar una relación exhaustiva de posibles casos dudosos, podríamos concluir citando los temas Tocando el arpa dorada de la Orquesta Nat Gonella (1943), o Raska$Y u$ de Bonet de San Pedro y los Siete de Palma (1943). En ambos se interpreta -o se busca la inspiración en- algún motivo de la Marcha fúnebre de Chopin; siendo mucho más reconocible en el primero que en el segundo. Además, conviene señalar que tal circunstancia es meramente puntual en los registros citados. Teniendo en cuenta todo ello, cabría preguntarse si era suficiente la recreación, o bien la mera invocación del tema clásico en un breve intervalo de tiempo, para que tuviera lugar la prohibición.

\section{EL PERSONAL QUE LLEVARÍA A CABO LA CENSURA}

\section{1. Problemas de competencia}

Como sabemos, la orden que nos ocupa procedía del Sindicato Nacional del Espectáculo. En base a ello, cabría entender que la censura se vertebraría en torno a los organismos dependientes de aquel. De ello da cuenta la propia norma, en cuyo texto se solicitaba a las jefaturas de los sindicatos que comunicasen toda infracción a la Jefatura Nacional. En esta línea se desarrollan también noticias como la que publicitaba la prohibición en Las Palmas de Gran Canaria, en cuyo texto se señalaba que la vigilancia tendría lugar desde la jefatura de la Sección de Músicos del Sindicato Local del Espectáculo. Del mismo modo, según se constataba en el Boletín del Sindicato Nacional del Espectáculo, las instrucciones sobre la cuestión que nos ocupa se enviaron a los Sindicatos Locales de Espectáculos para que, desde allí, se entregaran a los enlaces sindicales con el fin de que las obligaciones fueran cumplidas (“Grupo de Música. Actividades [...], 1942, p. 45). Todo ello parece corresponderse con la Ley de Bases de la Organización Sindical (1940, artículo 16), que establecía entre las funciones de las Centrales Nacional-sindicalistas, directamente o por medio de los Sindicatos y Hermandades Sindicales Locales, las siguientes:

"Séptimo.- Realizar, en su esfera, todas las otras funciones que su mando nacional le encomiende.

Octavo.- Orientar y vigilar el funcionamiento de los Sindicatos Locales, que secundarán, en su esfera, las funciones de los Nacionales correspondientes y, en su caso, asumir estas funciones donde no exista diferenciación sindical.” 
Sin embargo, lo cierto es que, como veremos en los siguientes espacios, al menos en una parte considerable, la censura se desarrollaría desde las Delegaciones Provinciales, que recibían instrucciones de la Delegación Nacional de Propaganda. La documentación consultada evidencia que esta última había promovido la prohibición que estudiamos. El 21 de mayo de 1942, Torres López, en calidad de Consejero Nacional en Funciones de Delegado Nacional de Propaganda, firmaba un oficio dirigido a la "Sección Musical" (probablemente debamos entender Sección de Propaganda Oral y $\mathrm{Musical}^{20}$ ), en el que consideraba indispensable la elaboración de una orden que prohibiera los "atentados incalificables" perpetrados con la adaptación de obras de "la Literatura Musical" a la música bailable; en perjuicio de la "formación del gusto musical del pueblo" (Oficio de la Delegación Nacional de Propaganda [...], 21 de mayo de 1942) ${ }^{21}$. Sin embargo, la orden procedió finalmente del Sindicato Nacional del Espectáculo, y por ello cabría concluir que la censura desarrollada desde las Delegaciones Provinciales no tenía fundamento normativo. La Ley de Bases de la Organización Sindical (1940, artículo 18) recogía las funciones del Sindicato Nacional, y en ellas no se aprecia conexión con la Delegación Nacional de Propaganda. Es cierto que según el Decreto que reconocería al Sindicato Nacional del Espectáculo como corporación de Derecho público, el Ministro Secretario general del Partido dictaría disposiciones para que se llevasen a cabo relaciones entre el Sindicato Nacional del Espectáculo y la Delegación Nacional de Cinematógrafo y Teatro de la Vicesecretaría de Educación Popular, coordinando la propaganda y censura de la última con la parcela económica de la producción atribuida al Sindicato Nacional del Espectáculo (“Decreto de 19 de febrero de 1942 [...]”, 1942, artículo 4). Sin embargo, al menos hasta donde llegamos a conocer, cuando apareció la orden no se había publicado ninguna disposición en el sentido descrito, ni a propósito de la Delegación Nacional de Propaganda, que es la que nos interesa principalmente en este trabajo.

Lo cierto es que el problema de las competencias tenía una proyección más general, pues no parece que estuvieran claras las asumidas por la Vicesecretaría de Educación Popular en materia de censura (recordemos que de ella dependía la Delegación Nacional de Propaganda, que instruía en tareas de censura a las Delegaciones Provinciales). En este sentido, resulta interesante señalar que a finales de 1943 -más de un año después de que apareciera la orden que nos interesa- el Vicesecretario de Educación Popular, Arias Salgado, proponía un proyecto

\footnotetext{
${ }^{20}$ En el organigrama de la Vicesecretaría de Educación Popular no aparece, como tal, la "Sección Musical", pero sí la que señalamos en el texto. Sobre la estructura del órgano Bermejo Sánchez, 1991, p. 76.

${ }^{21}$ El documento no ocultaba la inspiración, en él se citaba como ejemplo lo acontecido en Alemania.
} 
para delimitar las competencias entre la Falange y el Ministerio de Gobernación (Carta de G. Arias Salgado, 1943), y que a mediados de 1944 apareció en el Boletín Oficial del Estado un Decreto que pretendía "evitar conflictos de atribuciones en esta materia entre los organismos estatales a los que están confiados unos y otros servicios" ("Decreto de 4 de agosto de 1944 [...], 1944, exposición inicial). Entre las funciones atribuidas por aquella norma a la Vicesecretaría de Educación Popular encontramos, por ejemplo, toda la censura radiofónica y la dirección de la propaganda estatal en el medio ("Decreto de 4 de agosto de 1944 [...], 1944, artículo 3). Además, establecía que el Ministerio de la Gobernación debía traspasar en un mes a la Vicesecretaría de Educación Popular los servicios que tuviera confiados hasta la fecha ("Decreto de 4 de agosto de 1944 [...], 1944, disposición transitoria) 22. Todo ello, conviene destacarlo, aconteció dos años después de que apareciera la disposición que estudiamos.

Tiempo antes, algunos meses después de la publicación de la orden que nos ocupa, la problemática competencial había quedado evidenciada con un oficio secreto, en cuyo texto se recordaba que la Dirección General de Seguridad había comunicado al Vicesecretario de Educación Popular lo siguiente:

\begin{abstract}
"Con objeto de facilitar una mayor rapidez en la marcha general del Servicio. Ruego a V. I. ordene que todas las comunicaciones de esa Vicesecretaría de su digno cargo, relacionadas con la Censura Gubernativa, sean dirigidas al Excmo. Sr. Director General de Seguridad, Sección 4, Censura, Servicio de Información"23 (Oficio secreto, 22 de marzo de 1943, 1943).
\end{abstract}

Como vemos, se solicitaba remitir la documentación a la "Sección 4a, Censura, Servicio de Información", es decir, según pensamos, una de las cuatro comisarías generales que conformaban la ramificación de la Dirección General de Seguridad: "Fronteras, Información, Orden Público e Identificación" ${ }^{24}$. De tal solicitud cabría concluir que la competencia para llevar a cabo la censura era del Gobierno, y no de la Vicesecretaría de Educación Popular. Debe tenerse en cuenta que se hace alusión a la "Censura Gubernativa", que el Ministerio de Gobernación había asumido los servicios del Ministerio de Orden Público, suprimido en 1938, y que entre los de aquel (después direcciones generales) encontramos el de seguridad ("Ley [de organización de la Administración Central del Estado]”, 1938, artículo 8).

Incluso desde la Vicesecretaría de Educación Popular parecía reconocerse la atribución de competencias constatada en el oficio secreto. Por una parte, porque en la respuesta a la

\footnotetext{
${ }^{22}$ Considera esta normativa, así como las circunstancias derivadas del traspaso de competencias, Montoro Bermejo, 2015, pp. 339 y ss.

${ }^{23}$ El texto está subrayado desde "Censura Gubernativa" hasta el final de la transcripción.

${ }^{24}$ Tomamos la información de Gómez Bravo, 2014, p. 50.
} 
solicitud se informaba de que en la Delegación Nacional de Propaganda no había normas de censura, "sino orientaciones para la misma". Con ello parece restarse relevancia a las tareas de censura que se estaban desarrollando. En todo caso, tal declaración no se ajustaba precisamente a disposiciones como, por ejemplo, la Circular 95 (1942), en cuyo título puede leerse Normas Sobre Censura radiofónica. Por otra parte, cabría añadir que el mismo documento informaba de que se adjuntaban las circulares que versaban sobre publicidad, censura de radio y de libros ([Acuse de recibo de oficio secreto], 1943). Sabemos concretamente de qué disposiciones se trataba, pues la documentación está enumerada de forma manuscrita, comenzando por el oficio secreto y el acuse de recibo del mismo. Resulta interesante constatar que en esta relación no aparece la orden que nos interesa. Si del desarrollo expuesto cabría concluir que existían problemas de competencia en cuanto a la censura que había asumido la propia Vicesecretaria de Educación Popular, con mayor razón podría presentarse dicha afirmación en lo que respecta a la orden a la que dedicamos este trabajo, que había emanado de un órgano diferente, y cuyo control, asumido de facto, no se manifestaba ni de forma interna.

\section{2. Órdenes ad hoc y sus problemas}

Como ya señalamos en el apartado precedente, al menos hasta donde alcanzamos a conocer, la censura de la orden desarrollada por parte de las Delegaciones Provinciales no tenía fundamento normativo. La ausencia queda además confirmada si tenemos en cuenta las órdenes ad hoc que recibieron aquellas para desarrollar su tarea. De ello ofrece prueba el texto que transcribimos a continuación, tomado de un oficio enviado desde la Delegación Nacional de Propaganda a la Delegación Provincial de Cuenca:

"te comunico que, en el desempeño de las funciones que tienes designadas cercad [entendemos 'acerca'] de los espectáculos y de las Emisoras de Radio, debes velar por el cumplimiento de la orden dada por el Sindicato Nacional del Espectáculo, comunicando además a esta Delegación Nacional las medidas adoptadas para cumplimentarlo." (Oficio de la Delegación Nacional de Propaganda [...], 2 de octubre de 1942a)

Teniendo en cuenta documentos como el transcrito, en principio cabría entender que la Delegación Nacional de Propaganda habría recibido instrucciones desde el Sindicato Nacional del Espectáculo, con el fin de que se desarrollase -o se colaborase con- la censura por parte de las Delegaciones Provinciales. Sin embargo, no debió acontecer de aquella manera. La orden ad hoc recientemente transcrita no surgió a partir del itinerario señalado, sino del siguiente modo. En una nota de servicio interior de la Sección de Asuntos Generales de Propaganda se informaba de que el Delegado Provincial de Cuenca había dado cuenta en su informe semanal 
de espectáculos taurino-musicales, en los que estaban teniendo lugar prácticas contrarias a las disposiciones en vigor. Concretamente, en el documento puede leerse lo siguiente: "continúa interpretando obras musicales de autores clásicos acopladas al jazz". En la misma nota se reclamaban también instrucciones para proceder ante tales transgresiones de la normativa (Nota de servicio interior [...], 19 de septiembre de 1942). Sorprendentemente, como respuesta a lo anterior se solicitó que el Delegado Provincial de Cuenca ampliase los detalles (Nota de servicio interior [...], 19 de septiembre de 1942) ${ }^{25}$. La petición quedaría redactada en un oficio de la Sección de Propaganda Oral y Educación Musical (firmado por el Consejero Nacional en Funciones de Delegado Nacional de Propaganda), en el que se pedía más información, dado que no se tenía constancia de lo que se decía desde aquella Delegación Provincial (Oficio de la Delegación Nacional de Propaganda [...], 23 de septiembre de 1942). Quizá pudiera pensarse que con ello se estaba haciendo alusión a los pormenores de los hechos denunciados, pero si se tiene en cuenta la respuesta al requerimiento cabría entender que no fue así ${ }^{26}$ :

"Como aclaración pedida por ese departamento a lo que manifestaba en el informe semanal $[\ldots]$ sobre la prohibición de interpretar música clásica acopladas [entendemos 'acoplada'] al jazz, según me informa el Jefe del Departamento de P. Oral y E. Musical de esta Delegación Provincial, dicha prohibición ha sido dictada por el Sindicato Nacional del Espectáculo."

La documentación analizada descubre, por tanto, que, al menos en parte de la Delegación Nacional de Propaganda ni siquiera se conocía la orden del Sindicato Nacional del Espectáculo, y que aquella, si seguimos el caso analizado, no informó de la disposición a la Delegación Provincial. Fue precisamente esta última la que dio cuenta de las infracciones y de la norma que establecía la prohibición; probablemente, cabría entender, porque se había tenido conocimiento de aquella por otros cauces. A finales de septiembre de 1942 la Delegación Provincial de Cuenca comunicaría que en las "Galas Artísticas ejecutan obras de autores clásicos acopladas al jazz" (Oficio de la Delegación Provincial de Cuenca [...], 25 de septiembre de 1942). Pocos días después, ahora ya sí, desde la Sección de Propagada Oral y Educación Musical de la Delegación Nacional de Propaganda, se respondería con el oficio que incluiría el texto transcrito al comienzo de este apartado.

Como ya señalamos, el recurso a las órdenes ad hoc, así como las circunstancias expuestas, confirman la carencia de base normativa que venimos considerando. Pero además

\footnotetext{
${ }^{25}$ Esta respuesta, recogida en el documento citado, tiene fecha de 23 de septiembre de 1942.

${ }^{26}$ Tomamos la información de la siguiente referencia, que recaba el contenido del informe de la última semana de septiembre llevado a cabo por el Delegado Provincial de Cuenca: Nota de servicio interior [...], 8 de octubre de 1942.
} 
de ello, y de demostrar la descoordinación interna, aquellas también darían lugar a otros problemas, pues en ocasiones iban más allá de lo que había establecido la propia orden. Podemos, por ejemplo, considerar la siguiente respuesta de la Delegación Nacional de Propaganda, relativa a una cuestión planteada desde la Delegación Provincial de Valencia:

\begin{abstract}
"te comunico que debes velar celosamente por el cumplimiento de la orden emanada del Sindicato Nacional del Espectáculo. Si bien dicha orden se refiere únicamente a las adaptaciones al género de «jazz» de las obras de repertorio clásico, debes procurar que en todas las manifestaciones musicales, especialmente en las emisiones de radio, se respete el sano criterio impuesto por el Sindicato Nacional del Espectáculo." (Oficio de la Delegación Nacional de Propaganda [...], 2 de octubre de 1942b).
\end{abstract}

Como puede verse, en la comunicación no se ordena únicamente cumplir con la norma procedente del Sindicato Nacional del Espectáculo, sino también actuar conforme al "sano criterio" que aquel había impuesto. El añadido es vago y podría dar lugar a varias interpretaciones. De un lado, cabría considerar que con él se estaba solicitando la prohibición de los temas que interpretasen obras clásicas con jazz, y también de aquellos que hicieran lo propio con los otros ritmos bailables. No obstante, frente a esta opción podría objetarse que la orden se refiere a orquestas de jazz, pero también a las de baile, y que por tanto su propio texto da a entender tal circunstancia, sin necesidad de recurrir al "sano criterio" del Sindicato Nacional del Espectáculo.

Un análisis de las manifestaciones que rodearon a la norma que nos interesa, y que ya consideramos en el apartado dedicado a la publicación, publicidad y propaganda, aporta razones para establecer una interpretación diferente y más probable. Como vimos, el anuncio de la norma en los medios apareció frecuentemente junto a comentarios que denostaban al jazz en general. Si esto es así, cabría entender que la orden ad hoc estaba solicitando, no ya únicamente que se prohibiesen las interpretaciones de música clásica por orquestas de jazz, sino todos los temas musicales que pudieran enmarcarse en el jazz. En tal caso, en principio cabría señalar que la orden ad hoc se había planteado en la línea de lo que, de forma coetánea, prescribiría la Circular 95, que entraría en vigor en octubre de 1942. Sin embargo, conviene precisar que en esta última disposición no se prohibía el jazz propiamente, sino la "música negra” (Circular 95, 1942); una expresión que, como después se señalaría, no alcanzaba a todas las composiciones de jazz, sino a algunas con unas características determinadas (Centenera Sánchez-Seco, 2020, pp. 11 y ss.). Por otra parte, cabría apuntar que la Circular 95 circunscribía su prohibición al ámbito radiofónico, y que en el caso analizado, si bien se pone especial énfasis en aquel, el mandato alcanzaba al resto de contextos. Con todo ello, la orden ad hoc que nos ocupa añadiría 
a los fracasos normativos constatados las inconsistencias de su texto con respecto a la norma del Sindicato Nacional del Espectáculo y a la Circular 95.

Otro caso interesante nos lleva a centrar la atención en la Delegación Provincial de Guipúzcoa, desde donde se había solicitado información acerca de "cuantas disposiciones hayan salido sobre prohibición de ejecutar en bailes y lugares públicos transcripciones de otras clásicas de autores inmortales" (Oficio de la Delegación Provincial de Guipúzcoa [...], 20 de octubre de 1942). Sin duda, la solicitud traía causa del desconocimiento de la regulación en cuestión, en este caso por parte de la Delegación Provincial. A propósito de ello, conviene reseñar que el oficio que reclamaba la información está datado casi dos meses después de que la norma fuera publicada. En todo caso, para los intereses que ahora tenemos, lo especialmente relevante es la respuesta dada, en cuyo texto leemos lo siguiente:

\footnotetext{
"en caso de ser contravenida la disposición que prohíbe la interpretación de bailables inspirados en melodías de autores clásicos o románticos, puedes intervenir las partituras retirándolas de los correspondientes archivos y hasta suspender la actuación de la orquesta infractora, en casos de reincidencia." (Oficio de la Delegación Nacional de Propaganda [...], 31 de octubre de 1942).
}

Como puede apreciarse, las sanciones, ausentes en la norma que estudiamos, aparecen en este caso por medio de una orden ad hoc; un detalle que de nuevo manifiesta el recurrente desprecio hacia las normas, y cuya redacción abre la puerta a la arbitrariedad. Por una parte, debe tenerse presente que nos encontramos ante una comunicación puntual, dirigida a una Delegación Provincial, y que otras podrían haber procedido de diferente modo. Por otra parte, conviene reparar en el detalle de que en el texto se utiliza el verbo 'puedes' -no 'debes'-, que confirma que se tenía capacidad para imponer las sanciones descritas, pero no una obligación para ello; con lo cual el resultado final dependía del parecer personal de quien llevase a cabo la censura de forma directa.

Por lo demás, teniendo en cuenta la respuesta en cuestión cabría preguntarse cómo debía procederse en el caso de que se estuviera emitiendo un disco con la música prohibida. La ausencia de posibles sanciones para dicho supuesto en el documento anterior, probablemente sea una muestra de la insuficiencia, en términos de comunicación, de aquella nota que apareció en la prensa, según la cual la prohibición comprendía también la emisión de discos en público.

\section{LA ORDEN EN LA PRÁCTICA}

\section{1. Un acercamiento al (in)cumplimiento}


Un análisis detenido de la documentación que hemos podido consultar ofrece detalles que inducen a pensar que la prohibición se tomó en consideración en numerosos ámbitos. Resulta interesante constatar que, por ejemplo, en lo que concierne a la parcela radiofónica, en varias ocasiones se emitiría el tema Farewell Blues de la Orquesta de Benny Goodman (como muestra, puede verse [Cuaderno de emisiones de] Radio Madrid, 4 de octubre de 1943), y que no aconteció del mismo modo con el titulado Bach Goes in Town, que ya consideramos anteriormente, y que se encontraba en la otra cara del disco que recogía el primer tema (Orquesta Benny Goodman, 1942). La circunstancia constatada probablemente se debió a que, al menos en algunas emisoras, se podría haber considerado que el tema Bach Goes in Town había quedado prohibido con la orden. Como señalamos anteriormente, la cuestión no estaba clara, pero la cita del autor clásico en el título, unida al dato de que la interpretación corría a cargo de uno de los paradigmas del jazz del momento, debieron resultar determinantes en circunstancias como la considerada.

Por otra parte, si centramos la atención en el panorama de la producción discográfica podría decirse que, aunque como también señalamos, la orden no había establecido explícitamente si alcanzaba a aquel, determinados detalles invitan a pensar que se hizo una interpretación extensiva de aquella, al menos en parte. La mayoría de las referencias consultadas para este estudio, procedentes de discográficas españolas y cuya música pudiera entenderse que entraba dentro de la prohibición, tienen una fecha de edición que llega hasta el año 1942 (en el cómputo consideramos los registros que ofrecen la datación de su publicación). Como sabemos, fue entonces cuando apareció la orden que estamos estudiando. Frente a tal planteamiento, podría objetarse que un año después aparecieron los temas Tocando el arpa dorada de la Orquesta Nat Gonella y Raska-Yu de Bonet de San Pedro y los Siete de Palma. Sin embargo, resulta interesante constatar que en estos casos el reflejo de la música clásica en la interpretación es breve y puntual. Probablemente por ello, las discográficas consideraron que no pasaban la línea roja de la prohibición y, por tanto, los editaron.

No obstante, aun a pesar de detalles como los anteriores, con los que cabría concluir que la orden se estaba observando en determinados ámbitos, en base incluso a una interpretación extensiva $^{27}$ de la misma, lo cierto es que no en todo caso debió acontecer de tal modo. En un

\footnotetext{
${ }^{27}$ Sobre la misma, por ejemplo, Rodríguez-Toubes Muñiz, 2019, pp. 74, 75. Cabría puntualizar, aplicando lo que señala esta referencia, que en el caso relativo al tema Bach Goes in Town, quizá más que de interpretación extensiva debería hablarse de analogía, pues no se trata de una interpretación de una obra clásica, como ya señalamos anteriormente.
} 
programa emitido en Radio Zaragoza, Laguna Azorín presentaba su percepción sobre lo que estaba ocurriendo en los siguientes términos:

\begin{abstract}
"se están cometiendo verdaderos crímenes artísticos parodiando obras maestras para llevarlas al ritmo sincopado, inarmónico y estridente del «jazz», en la seguridad de que si los autores de lo ridiculizado levantaran la cabeza lanzarían el máximo anatema a quienes cometen tal sacrilegio artístico" (Laguna Azorín, 1943).
\end{abstract}

La información es interesante para el espacio que nos ocupa, pues forma parte de un texto fechado el 22 de noviembre de 1943; es decir, un año y dos meses después de que se hubiera publicado la orden del Sindicato Nacional del Espectáculo. En base a dicho testimonio cabría entender que en numerosas ocasiones la prohibición no se estaba cumpliendo. La circunstancia se confirma con algunos datos aportados ya en este estudio. Viene al caso recordar las infracciones en festivales taurino-musicales, o en galas de espectáculos, de las cuales había dado cuenta la Delegación Provincial de Cuenca.

Por otra parte, el análisis de los cuadernos de emisiones radiofónicas ofrece razones para seguir pensando en el mismo sentido. Presentaremos muestra de ello en el siguiente espacio, donde consideraremos numerosos temas que quedarían censurados. No obstante, antes quisiéramos señalar que en ocasiones, los guiones radiofónicos no incluían información que podría resultar determinante. Así acontece en uno emitido en Radio Madrid, en el cual se establecen comparaciones entre el jazz y el vals contextualizadas en una conversación que reúne a un abuelo, su nieto y un amigo. El primero critica al jazz por su estruendo, discordancia, vínculo con los cocktails y con las personas negras; al tiempo que cita a Stravinsky como compositor moderno elegante. Frente a ello, su nieto se presenta como defensor del jazz, la música de la juventud y de la vida moderna, nerviosa e industrial. Entre las confrontaciones de argumentos interviene el amigo, que trata de reconciliar posturas del siguiente modo:

\footnotetext{
“¿No es cierto que la música es el lenguaje de las almas? ¿Por qué, entonces, no han de hablar juntas el alma moderna y el alma antigua? ¡Escuchad! En esta composición, que es el último grito lírico, hay ritmo y melodía... Para los de hoy, y para los de ayer...!" (Pulido, 1942).
}

Cabría pensar que la introducción transcrita precedía a una composición en la que podría observase una mixtura entre la música moderna y la clásica. Sin embargo, resulta interesante constatar que a continuación del texto puede leerse únicamente el indicativo de 'Música'. Más allá de ello, no hay información sobre la composición concreta que se emitiría. En nuestra opinión, probablemente no era un tema prohibido por la orden que nos ocupa; su 
contextualización en el ámbito lírico así parece indicarlo. El análisis del texto transcrito invita a pensar que podría haberse tratado de una composición inspirada en algún sentido en el jazz, aunque sin perder la perspectiva musical citada en el documento ${ }^{28}$. En un momento en el que las críticas a aquel estaban alcanzando su punto más álgido, quizá se estimó que lo más conveniente era evitar la cita concreta de la referencia musical que se iba a emitir.

En el programa que recoge la información anterior no hay signo alguno de censura, pero los detalles no pasaron desapercibidos en otros casos. Representativo de ello es un espacio que incluye el tema Duo de amor, por Ljungberg, Widdop y Orquesta Sinfónica, y Cabalgata, a cargo de Orquesta sinfónica. En este lugar puede leerse, escrito de forma manuscrita, "Música de Wagner", y a continuación del primer tema un interrogante grande. Probablemente se dudaba acerca de si se trataba de la música del compositor clásico, o de una interpretación de la misma por parte de una orquesta. Ello justificaría la pregunta que aparece, también de forma manuscrita, al pie de la entrada, y que confirma las sospechas de quien estaba llevando a cabo la censura: "Seran frag. [entendemos 'fragmentos'] de la «Walkiria» verdad?" ([Cuaderno de emisiones de] Radio Barcelona, 1 de enero de 1944). Muy probablemente, pensamos que fue asi $^{29}$, pero la susceptibilidad demostrada da muestra de que la censura, al menos en determinados ámbitos, no se proyectaría con carácter liviano.

\section{2. Temas censurados}

A lo largo de la investigación realizada hemos localizado varios temas que quedaron censurados. Consideramos que la constatación de las referencias en cuestión resulta interesante, pues es una aportación más al análisis de los problemas de eficacia de la orden que nos ocupa, además de una contribución al conocimiento de la censura desarrollada a partir de aquella. No obstante, en este espacio pretendemos también ofrecer algunas ideas sobre los recursos que podrían haberse utilizado a la hora de aplicar la norma.

No hay duda de que quienes llevaron a cabo la censura reparaban en los documentos que obligadamente debían presentarse para controlar la actividad musical. Así, en el caso de la radio, los cuadernos de emisiones que recogían los temas de los espacios musicales que se emitirían. En numerosas ocasiones, estos documentos aportaban información determinante. En un programa de Radio Barcelona, bajo el título de "Jazz al piano y canciones italianas", hemos

\footnotetext{
${ }^{28}$ Podría haberse tratado de alguna obra sinfónica inspirada en el jazz; un tipo de composición que, según lo dispuesto un año después, no debería considerarse prohibida (Centenera Sánchez-Seco, 2020, pp. 23-27).

${ }^{29}$ Así lo demuestra la siguiente referencia: Gota Ljumberg y Walter Widdop con acompañamiento de orquesta, 1930.
} 
localizado la siguiente entrada, que presenta un tema interpretado por el pianista Jorge Halpern: “«Romeo y Julieta» Fox de Tschaicowsky [entendemos 'Tchaicowsky']”. Aun cuando no parece que se tratase de una orquesta de jazz ni de baile, sino de un pianista, la información transcrita parece que fue suficiente para la censura. El nombre del compositor clásico aparece enmarcado en un rectángulo, a partir del cual se traza una línea dirigida a la siguiente exclamación: ‘¡ojo!' ([Cuaderno de emisiones de] Radio Barcelona, 16 de diciembre de 1942).

Incluso determinados títulos debieron resultar determinantes para hacer efectiva la prohibición. En un programa fechado el 23 de octubre de 1942, localizamos censurados los temas Guerra de valses y Marcha sobre motivos de Juan Strauss, interpretados por la Orquesta de Heric Harden. En el cuaderno de emisiones puede verse una flecha que se dirige a ambos títulos, y que remite al lateral de la página, donde puede leerse con letras manuscritas lo siguiente: "Este disco no se puede radiar" ([Cuaderno de emisiones de] Radio Barcelona, 23 de octubre de 1942). Curiosamente, la comparación entre la información que recogía la entrada censurada, y la que aparece en el disco que incluía ambos temas (Heric Harden, 1934), descubre que en la primera, en lo que respecta al segundo tema, se había omitido la palabra francesa Potpourri, con la cual empezaba su título, castellanizándose además el nombre del compositor clásico (Juan, en vez de Johann). Probablemente con ello se trató de sortear la censura, estricta en lo que respecta al uso de lenguas extranjeras (Circular 95, 1942), pero de ser así, aquella disposición no fue suficiente para lograr el objetivo.

Como adelantábamos, en el caso que consideramos la censura de los temas debió motivarse por sus títulos, que claramente remiten a la música clásica. A ello cabría añadir que la agrupación musical que los interpretaba podría considerarse una orquesta de baile. No obstante, debe señalarse que en lo que respecta al primer tema, no se llevó a cabo una aplicación de la norma en un sentido finalista, en base a la cual debía entenderse que quedaba prohibida la interpretación de música clásica con jazz o ritmos bailables. Guerra de valses no transcurre por dichos registros musicales, su audición demuestra que se trata simplemente de un vals de Strauss (Heric Harden, 1934); aunque eso sí, a cargo de una orquesta de baile. En atención a ello, podría entenderse que en este caso, a la hora de aplicar la orden se consideró que esta última prohibía la interpretación de música clásica por parte de orquestas de jazz o de baile. De este modo, se estaría llevando a cabo una aplicación normativa en base a una interpretación literal. No obstante, la prohibición quizá tuvo su razón de ser en otras causas.

Quien realizó la censura en el caso que nos ocupa, podría haber tenido en mente una interpretación finalista de la norma, en el sentido anteriormente apuntado; pues, como ya señalamos, era la que preponderaba en los comentarios coetáneos a la orden. Sin embargo, quizá 
pasó por alto que Guerra de Valses era simplemente la interpretación de un vals; aun cuando así se constataba, tanto en el disco que recogía el tema, como en el catálogo discográfico que lo incluía ${ }^{30}$. Se debió entender, por el contrario, que se trataba de una adaptación de un tema clásico a un ritmo bailable o al jazz. El otro tema del disco, Marcha sobre motivos de Juan Strauss, sí podría tener esta última calificación, como así lo explicita el propio título. Tal circunstancia quizá podría haber dado lugar a pensar que la otra cara del disco, que recogía Guerra de valses, tenía el mismo planteamiento musical. Si se acepta esta propuesta, con ella cabría concluir que en casos como el expuesto el desconocimiento musical, así como la ausencia de un examen detenido de los posibles recursos que pudieran consultarse, resultaron determinantes en el desarrollo de la censura. De otro modo, si el tema se hubiese escuchado, o si se hubiera recabado información sobre el mismo, probablemente no se habría prohibido.

La censura que recayó sobre Guerra de valses no se percibe en otros temas, en los cuales también se interpretaba música clásica por orquestas de baile, sin ser adaptada al jazz o a ritmos bailables. Así lo prueba, por ejemplo, otra entrada de la misma emisora donde, sin tacha alguna, aparece el siguiente tema de la Orquesta New Mayfair: "«POPURRÍ DE VALSES ANTIGUOS»Vals Naila, de Delibes, «Aprende a perder» de Kreisler. «Mi Héroe» de Oscar Strauss" ([Cuaderno de emisiones de] Radio Barcelona, 15 de octubre de 1943). Como puede verse, se trata de una composición que aglutina varios valses clásicos, y que además se interpreta por una orquesta de baile. Este último dato resulta totalmente explícito en la primera parte de la entrada del programa que recoge el tema, donde aparece también el titulado Popurrí de Onesteps ([Cuaderno de emisiones de] Radio Barcelona, 15 de octubre de 1943) ${ }^{31}$, interpretado por la orquesta citada anteriormente y que, como puede observarse, alude a un tipo de música bailable. Pero la inconsistencia en la censura iría más allá. Así lo demuestra el hecho de que tanto Guerra de valses como Marcha sobre motivos de Juan Strauss, referencias que habían quedado vetadas en el caso anterior, aparecieran nuevamente en la misma emisora dos meses y algunos días después, aunque en esta ocasión sin signo alguno de censura ([Cuaderno de emisiones de] Radio Barcelona, 3 de enero de 1943).

Además de tener en cuenta la información recogida en los cuadernos de emisiones, cabría añadir que en ocasiones, a la hora de llevar a cabo la censura también podrían haberse consultado discos. Recordemos que en uno de los casos tratados anteriormente la nota de la

\footnotetext{
${ }^{30}$ En el disco el tema se presenta como un vals, con su autoría entre paréntesis: "(Hans May y J. Strauss)" (Heric Harden, 1934). Del mismo modo acontece en el catálogo Odeón, 1934. Tal disposición contrasta con la que aparece a propósito de la Marcha sobre motivos de Juan Strauss, que tanto en el disco como en el catálogo discográfico aparece como un arreglo.

${ }^{31}$ Los temas en cuestión se recogen en el siguiente disco: Orquesta New Myfair, 1942.
} 
censura aludía a "Este disco", a la hora de plantear la prohibición (aunque luego no se analizase la referencia en cuestión convenientemente). El uso de este recurso pensamos que se podría considerar a propósito de otro programa de Radio Barcelona emitido a finales de octubre de 1942, donde están censurados los temas Mi última romanza e Ilusión de Rafael Medina. Ambos aparecen tachados, y a continuación, entre paréntesis, puede leerse lo siguiente: "no se puede dar por estar sacada de música seria" ([Cuaderno de emisiones de] Radio Barcelona, 27 de octubre de 1942). La revisión del disco que incluye ambos temas invita a pensar que, probablemente, la información que recogía dicho registro sobre aquellos podría haberse utilizado por la censura para detectar las piezas prohibidas. En el caso que nos ocupa, las etiquetas del disco descubren la conexión de los temas con la música clásica del siguiente modo: "Ilusión, fox lento sobre un tema de Chopin y Mi última romanza, fox lento sobre un tema de Tchaikowsky" (Rafael Medina y su Orquesta, 1942). Algo parecido puede decirse de la censura del tema Farándola, interpretado por la Orquesta Gran Casino. En esta ocasión, en el cuaderno de emisiones puede leerse "Prohibido. está basada en La Arlesiana de Bizet" ([Cuaderno de emisiones de] Radio Barcelona, 3 de diciembre de 1942); y en el disco que recoge la grabación se informa de que el tema en cuestión es un "foxtrot sobre un motivo de La Arlesiana, de Bizet" (Orquesta Gran Casino, 1942) . $^{32}$.

Más allá del medio radiofónico, la censura apareció también en otros ámbitos, como así lo demuestran algunos informes semanales de varias Delegaciones Provinciales, en el apartado que aquellos reservaban a la "Educación musical". Ejemplo de ello ofrece la información proporcionada por la Delegación Provincial de Orense, que en noviembre de 1942 comunicaba lo siguiente: "Ha sido rechazada, en virtud de lo ordenado por esa Delegación Nacional «Tristeza», adaptación musical de un motivo de Chopin” (Delegación Provincial de Educación Popular de Orense, segunda semana de noviembre de 1942). A finales del mismo mes, otro informe de la misma Delegación Provincial volvía a dar cuenta de la denegación del tema en cuestión por las mismas razones (Delegación Provincial de Educación Popular de Orense, última semana del mes de noviembre de 1942). Definitivamente, la publicación y publicidad de la orden no habían logrado la comunicación deseable a las posibles audiencias de aquella.

En casos como el expuesto podría pensarse también que se utilizó la información de los discos a la hora de establecer el veto. Concretamente, en el que recoge el tema Tristeza, un

\footnotetext{
${ }^{32}$ La hipótesis planteada cobra fuerza si se tiene en cuenta que en virtud de la Circular 83 (1942), las emisoras habían tenido que remitir numerosos datos de su historial; entre ellos, los "Elementos artísticos de que dispone [la emisora] (Orquesta y número de discos)". No obstante, cabría objetar que, como puede observarse, únicamente se solicitaba una relación cuantitativa de referencias.
} 
tango interpretado por Rafael Medina, con acompañamiento de la Orquesta Martín de la Rosa (1940), puede leerse que se trata de una adaptación del "Estudio n. ${ }^{\circ}$ 3, op. 10" de Chopin. No obstante, aun sin desechar dicha opción, consideramos que en contextos como el que nos ocupa la información podría haber llegado de las propias personas que pretendían interpretar los temas; probablemente desconociendo que existía una orden que los prohibía. Quizá sea interesante señalar que en la documentación consultada la prohibición de la referencia en cuestión aparece precedida de un texto en el que se informa de la presentación para censura de los temas que se interpretarían en los cafés y salones de variedades (Delegación Provincial de Educación Popular de Orense, última semana del mes de noviembre de 1942). No hemos localizado datos concretos sobre el tema Tristeza, pero por lo que conocemos de otros casos, en los documentos aportados a la censura aparecía información sobre el título de la composición, la categoría musical, la letra y su autoría. Probablemente, en el caso que nos ocupa, también se podría haber informado de que se trataba de una adaptación de un tema de Chopin.

Por lo demás, aunque no hemos localizado documentación sobre ello, cabría también considerar posibles denuncias sobre infracciones de la orden. Una editorial de la revista Ritmo, aparecida un mes después de que entrase en vigor aquella, animaba a contribuir con el Sindicato Nacional del Espectáculo, vigilando y denunciando "toda actuación musical delictiva" ("El Sindicato Nacional del Espectáculo y sus recientes disposiciones”, 1942, p. 3).

\section{3. La vaguedad lingüística relativa a la interpretación musical}

Como señalamos anteriormente, aun cuando en un principio la prohibición pudiera parecer clara, un análisis detenido sobre determinados casos descubría zonas de incertidumbre. A propósito de ello, resulta interesante reparar en cómo se afrontó tal circunstancia en la práctica y sus consecuencias. Concretamente, vamos a centrarnos en la vaguedad relativa a la interpretación de música clásica con jazz o ritmos bailables. Uno de los casos más representativos para advertir cómo se gestionó el problema en cuestión tuvo lugar a finales de 1942 en la Delegación Provincial de Murcia. Al parecer, allí se había recibido el tema Oye Mi Canción, Violeta, calificado como fox-trot, para que pasase la censura; pues se pretendía que fuese el fondo musical de un espacio publicitario para calzados. La presentación la hizo el propio comercio, Calzados Antón, por medio de "Publicidad Segura". Concretamente, en el informe que recoge los datos se decía que en el tema "van intercalados trozos de música sola de «La Traviata»". En principio el disco no se autorizó, pero desde la Delegación Provincial de 
Murcia se solicitaron instrucciones que indicasen en qué sentido proceder (Delegación Provincial de Murcia, primera semana del mes de diciembre de 1942) ${ }^{33}$.

El texto del informe parece indicar que la referencia musical citada incorporaba extractos de la obra clásica de Verdi, sin que fueran interpretados con música moderna; es decir, da a entender que el registro simplemente intercalaba extractos de La Traviata. Sin embargo, el análisis de las grabaciones del tema desmiente lo anterior, constatando con ello que el informe no fue preciso en su descripción. Si revisamos la interpretación de la Orquesta Martín de la Rosa, con el título de Violeta, comprobamos que el disco que la recoge informa de que se trata de una versión de Hör mein lied, Violetta!, que es un arreglo llevado a cabo por Othmar Klose y Rudi Lukesch, a partir de algunos motivos de La Traviata (Orquesta Martín de la Rosa, 1940). Los datos se confirman con la partitura del tema (Othmar Klose u. Rudi Lukesch, s. d.). No se trataba, por tanto, de una referencia que intercalaba extractos de La Traviata, como así daba a entender el documento de la Delegación Provincial.

Debe puntualizarse que la versión que aparece en el informe no era la recientemente citada, pues se trataba de un tango titulado Violeta, y en el documento se alude al fox-trot Oye Mi Canción, Violeta. Hemos localizado esta última referencia en el catálogo general de discos de Columbia publicado en 1942, se trata de una interpretación que corrió a cargo de Emilio Goya con acompañamiento de Tejada y su Gran Orquesta (Catálogo general de Discos Columbia, 1942). En otra catalogación del disco (Arévalo Molina, 2000, p. 92) aparece además la cita de Bernier, Emerick Klose, es decir, el arreglista citado anteriormente. Se trata, por tanto, de una referencia que reunía las características de la anterior en lo que respecta a la cuestión que nos ocupa, como así lo demuestra su audición (Emilio Goya con Tejada y su Gran Orquesta, s. d.) ${ }^{34}$. Por tanto, no estamos propiamente ante un tema que interpretase música clásica con un ritmo bailable; se trata de una versión de otro tema anterior que, a su vez, era un arreglo planteado a propósito de determinadas partes de La Traviata. Siendo esto así, cabría preguntarse si la referencia entraba dentro de la prohibición que, como sabemos, simplemente proscribía la interpretación de música clásica por parte de orquestas de baile y de jazz. ¿Cómo se resolvió la cuestión?

La respuesta se hizo esperar. En el informe semanal remitido por la Delegación Provincial de Murcia a mediados de diciembre se volvía a preguntar por el modo de proceder

\footnotetext{
${ }^{33}$ Este documento se considera en Pérez Zalduondo, 2011, p. 882; si bien no se alude a la respuesta dada a la solicitud.

${ }^{34}$ Debo mostrar mi agradecimiento a Julio Arévalo Molina, Director técnico de la BU.UCLM, que amablemente me proporcionó referencias gráficas y sonoras del disco - junto con las del que incluye Raska$y u$, citado más adelante, y también procedente de Radio Ciudad Real-, hoy parte del fondo citado.
} 
en los siguientes términos: "Espero tu respuesta acerca de la consulta sobre interpretación pública del disco titulado «Oye Mi Cancion Violeta» del que te hacía referencia en mi parte correspondiente a la primera semana del mes en curso" ([Delegación Provincial de Murcia, del 14 al 20 de diciembre de 1942]). El reclamo invita a pensar que probablemente no se tenía claro cuál debía ser la respuesta al caso; de hecho, la que se reportó así lo demuestra. La hemos localizado al final de una copia de la hoja del informe semanal que daba cuenta de la circunstancia en la primera semana de diciembre. En su parte inferior puede leerse de forma manuscrita lo siguiente: "Se contesta: que se podrá radiar el disco que nos pide «La Traviata»" ([Delegación Provincial de Murcia, primera semana del mes de diciembre de 1942]) ${ }^{35}$.

En la Delegación Provincial de Murcia debió persistir la duda, pues la información de aquella nota no respondía a la solicitud; no se había preguntado si se podía emitir la obra clásica -sobre lo cual no habría duda alguna-, sino el fox-trot inspirado en algunos arreglos desarrollados a partir de determinados extractos de aquella. Quizá en parte, el hecho de que la respuesta no fuera resolutiva pudiera traer causa de la redacción confusa con la que se había planteado la cuestión por parte de la Delegación Provincial. Más allá de ello, el análisis de la circunstancia indica que no se conocía la obra musical. De otro modo, la respuesta de la Delegación Nacional de Propaganda no se hubiera referido a algo que no se preguntaba.

Desconocemos si finalmente el tema llegó a emitirse como fondo musical para aquel espacio publicitario de calzados, pues la documentación no nos ha permitido llegar más allá. En todo caso, lo cierto es que no parece que se hubiera visto especial problema a la hora de difundirlo en otros ámbitos. Casi de forma coetánea al episodio anterior, quizá sin reparar en las posibles implicaciones normativas, o quizá sí, tomando entonces las precauciones oportunas, en la programación de Radio España Bilbao de comienzos de 1943 aparecería, sin apreciación alguna de censura, el tema Oye mi cancion Violeta. Casi con total seguridad, puede decirse que estamos también en esta ocasión ante la versión de Emilio Goya con Tejada y su Gran Orquesta, pues, aunque en el cuaderno de emisiones no se cita a dicha agrupación musical, el tema aparece con la calificación de fox ([Cuaderno de emisiones de] Radio España Bilbao, 19 de enero de 1943). Un año después puede verse también en Radio Barcelona, en esta ocasión se alude a la agrupación musical de Tejada, y se da a entender que la autoría de la composición es de Klose ([Cuaderno de emisiones de] Radio Barcelona, 21 de abril de 1944). Sin embargo, ni en este último caso, ni en el precedente, aparece nota alguna sobre La Traviata en los cuadernos de emisiones. Quizá por ello, y quizá también porque en esta ocasión la etiqueta del

\footnotetext{
${ }^{35}$ Se trata de la copia de la hoja del informe que hemos localizado en la signatura AGA (3)49.1 21/01532.
} 
disco tampoco aludía a la obra clásica (Emilio Goya con Tejada y su Gran Orquesta, s. d.), el tema pasó desapercibido para la censura.

Otras veces la respuesta que se dio a aquellos casos que pudieran ofrecer dudas fue más tajante. Así aconteció con el tema Raska-yu, que quedaría prohibido en Ciudad Real ${ }^{36}$; presentándose entre las razones para ello lo desagradable y chabacano de su música, que ofendía a la religión y que además incluía acordes de la "Marcha fúnebre"; algo considerado intolerable (De Calatrava, 1944, p. 2) ${ }^{37}$. Cabría precisar que en lo que respecta a la cuestión que nos ocupa, en el tema la melodía que pudiera relacionarse con la obra clásica citada únicamente ocupa los diez últimos segundos, y que no sigue estrictamente las afamadas notas compuestas por Chopin (Bonet de San Pedro y Los Siete de Palma, 1943). Sin embargo, en vista de la noticia parece que todo ello fue más que suficiente para considerar reprochable el detalle. No obstante, en esta ocasión convendría apuntar que en la motivación de la censura debieron desempeñar también un papel determinante los otros aspectos denunciados. Por lo demás, resulta interesante constatar que hasta aquel episodio, la censura no había reparado en el tema en cuestión; conviene tener en cuenta que la noticia del veto apareció dos años después de que hubiera entrado en vigor la orden a la que dedicamos este trabajo. Lo mismo debió acontecer en otros contextos radiofónicos, en cuyos cuadernos de emisiones hemos localizado el tema sin censura (así, por ejemplo, en [Cuaderno de emisiones de] Radio Barcelona, 30 de diciembre de 1943), incluso en el año 1944 ([Cuaderno de emisiones de] Radio Barcelona, 28 de enero de 1944), que fue cuando quedó prohibido en Ciudad Real. Una vez más, la circunstancia vuelve a dar cuenta del ritmo desacompasado, cuando no, libre, en la aplicación de la orden.

\section{CONCLUSIONES}

La orden del Sindicato Nacional del Espectáculo fue una de las primeras manifestaciones normativas de la censura del régimen en materia de música moderna. La ideología política de aquel, interesadamente revestida con música clásica, en un intento por seguir el caso nazi, cobraba entonces carta de naturaleza en el plano jurídico con la norma, para prohibir a las orquestas de jazz y de baile la interpretación de música clásica. Con ello, el análisis musical en lo intelectual quedaba arrinconado por un imperativo eminentemente político, reaccionario y excluyente, que da buena nuestra del carácter represivo del régimen.

\footnotetext{
${ }^{36}$ El disco que contiene el tema (Bonet de S. Pedro y los 7 de Palma, s. d.), procedente de Radio Ciudad Real, puede localizarse en Arévalo Molina, 2000, p. 260.

${ }^{37}$ Sobre otras críticas que recibió el tema puede consultarse Iglesias, 2017, pp. 162, 163; Torra, 2010 , p. 49.
} 
El estudio de la orden manifiesta un cúmulo de fracasos en el ámbito normativo. Aquella se publicó y se publicitó, pero todo ello no fue suficiente para que la norma llegase correctamente a sus audiencias. Además de ello, en ocasiones la publicidad, que podría considerarse un canal más cercano a aquellas, no sería fiel a la literalidad de la norma.

Desde el punto de vista linguiístico la orden suscita numerosas incertidumbres: no establece una tipificación adecuada ni sanciones, no deja claro si la prohibición alcanzaba a la reproducción de discos (si bien se aclaró después con una nota de prensa) y a la producción discográfica, incluye inconsistencias y da lugar a varias interpretaciones. Incluso en la propia formulación de la prohibición se advierte vaguedad lingüística, evidenciada con el análisis de temas que suscitan dudas acerca de si en ellos podría o no observarse interpretación de música clásica con ritmos jazzísticos o de baile.

Aunque la orden había emanado del Sindicato Nacional del Espectáculo, en una medida considerable su censura se llevó a cabo por las Delegaciones Provinciales, que dependían de la Delegación Nacional de Propaganda, integrada en la Vicesecretaría de Educación Popular. No hemos localizado base normativa que justifique la competencia para llevar a cabo dicha censura. Es más, existen razones jurídicas para pensar que la Vicesecretaría de Educación Popular la estaba desarrollando de facto.

A lo anterior cabría añadir que varias Delegaciones Provinciales recibieron órdenes ad hoc. El análisis de algún caso demuestra que, sorprendentemente, al menos en parte de la Delegación Nacional de Propaganda no se tenía conocimiento de la prohibición, y que esta última llegó mediante información reportada por las Delegaciones Provinciales. Por otra parte, hemos localizado órdenes ac hoc que ampliaron el ámbito de la prohibición y establecieron sanciones que no aparecían en el texto de la orden. Se trata, nuevamente, de aspectos que confirman el desprecio hacia las normas.

En lo que respecta a la puesta en práctica de la orden, cabe señalar que en determinados ámbitos radiofónicos y en la producción discográfica se debió secundar la prohibición, incluso en base a una interpretación extensiva de la misma. Sin embargo, la documentación ofrece pruebas de numerosos incumplimientos, algo evidenciado con los temas que quedaron vetados. A la hora de llevar a cabo su censura se debió recurrir a la información recogida en los cuadernos de emisiones radiofónicas, y probablemente también a la que aparecía en los discos editados, o la reportada obligadamente por parte de quienes pretendían interpretar temas. En todo caso, se trata de una censura que acusa reiteradas inconsistencias e incompetencias musicales en numerosos episodios. Más allá de ello, su funcionamiento sería también deficiente 
a consecuencia de la vaguedad lingüística apreciable en la propia prohibición, que en la práctica no siempre quedaría resuelta.

\section{FUENTES}

\section{1. Bibliografía}

ADORNO, Theodor. “Adiós al jazz”. En Escritos musicales V. Madrid: Akal, 2011.

ADORNO, Theodor. "Sobre el jazz”. En Escritos musicales IV. Madrid: Akal, 2008.

BERMEJO SÁNCHEZ, Benito. "La Vicesecretaría de Educación Popular (1941-1945): un «ministerio» de la propaganda en manos de Falange". Espacio, tiempo y forma, S. V. H. Contemporánea, vol. IV, 1991, pp. 73-96. Consultado en http://espacio.uned.es/fez/eserv.php?pid=bibliuned:ETFSerie5-16946BB6-A601-59A9-CD02AB4BD2DA2738\&dsID=Documento.pdf. Fecha de consulta: 06/11/2020.

CENTENERA SÁNCHEZ-SECO, Fernando. "La prohibición de Ébano swing y Cachita en el primer franquismo (Circular 98): mucho más que la simple censura de dos temas musicales". Cuadernos Electrónicos de Filosofía del Derecho, n. 41, 2019, pp. 65-96. Consultado en https://ojs.uv.es/index.php/CEFD/article/view/15439/pdf. Fecha de consulta: 04/12/2020.

CENTENERA SÁNCHEZ-SECO, Fernando “¿Qué debía entenderse por «música negra»en la censura franquista? Un estudio sobre la circular 146 (1943)”. e-Legal History Review, n. 32, 2020, pp. 1-51. Consultado en https://www.iustel.com/v2/revistas/detalle_revista.asp?id_noticia=422718. Fecha de consulta: 04/12/2020.

CIRILI, Alexandre. La estética del franquismo. Barcelona: Gustavo Gili, 1977.

GARCÍA, Jorge. El ruido alegre. Jazz en la BNE, [2013]. Consultado en http://www.bne.es/export/sites/BNWEB1/es/Micrositios/Exposiciones/Jazz/resources/img/est udio1.pdf. Fecha de consulta: 06/11/2020.

GIMÉNEZ CABALLERO, Ernesto. Arte y Estado. Madrid: Biblioteca Nueva, 2009.

GÓMEZ BRAVO, Gutmaro. Puig Antich: La transición inacabada. [Madrid]: Taurus, 2014.

IGLESIAS, Iván. La modernidad elusiva. Jazz, baile y política en la Guerra Civil Española y en el Franquismo (1936-1968). Madrid: Consejo Superior de Investigaciones Científicas, 2017.

IGLESIAS, Iván. “(Re)construyendo la identidad musical española: el jazz y el discurso cultural del franquismo durante la Segunda Guerra Mundial”. Historia Actual Online, n. 23, 2010, pp. 119-135. Consultado en https://www.historiaactual.org/Publicaciones/index.php/hao/article/view/503. Fecha de consulta: 06/11/2020. 
LAMBERT, Philip. Alec Wilder. American Composers. Chicago and Springfield: University of Illions Press, Urbana, 2013.

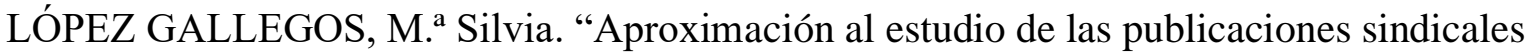
españolas desarrolladas durante el franquismo". Historia y comunicación social, n. 8, 2003, pp. 159-185. Consultado en https://revistas.ucm.es/index.php/HICS/article/view/HICS0303110159A/19355. Fecha de consulta: 06/11/2020.

MONTORO BERMEJO, Ignacio. Libertad de Expresión e Intervención Estatal en la Radiodifusión Española de la Primera Mitad del Siglo XX. Tesis Doctoral. Universidad de Murcia, 2015. Consultado en https://digitum.um.es/xmlui/bitstream/10201/45977/1/TESIS\%20IGNACIO\%202015.pdf. Fecha de consulta: 06/11/2020.

MOREDA RODRÍGUEZ, Eva. Music Criticsm and Music Critics in Early Francoist Spain. New York: Oxford Unversity Press, 2017.

MUÑIZ VELÁZQUEZ, José Antonio. “La Música en el Sistema Propagandístico Franquista”. Historia y Comunicación Social, n. 3, 1998, pp. 343-363. Consultado en https://idus.us.es/bitstream/handle/11441/17328/file_1.pdf?sequence=1\&isAllowed=y. Fecha de consulta: 07/11/2020.

NICHOLSON, Stuart. Jazz and Culture in a Global Age. [England]: Northeastern University Press, 2014.

PÉREZ ZALDUONDO, Gemma. "Música, censura y Falange: el control de la actividad musical desde la Vicesecretaría de Educación Popular". ARBOR Ciencia, Pensamiento y Cultura, vol. 187, n. 751, 2011, pp. 875-886. Consultado en http://arbor.revistas.csic.es/index.php/arbor/article/view/1357/1366. Fecha de consulta: 08/11/2020.

RODRÍGUEZ-TOUBES MUÑIZ, Joaquín, “La interpretación extensiva de la ley”. Derechos y Libertades, n. 40, 2019, pp. 67-108. Consultado en https://e-

archivo.uc3m.es/bitstream/handle/10016/29573/DyL-2019-40-

Rodrigueztoubes.pdf?sequence $=1 \&$ isAllowed=y. Fecha de consulta: 08/11/2020.

SELVA, Enrique. “Introducción”. En Giménez Caballero, Ernesto. Arte y Estado. Madrid: Biblioteca Nueva, 2009.

TACKLEY, Catherine. Benny Goodman's Famous 1938 Carnegie Hall Jazz Concert. Oxford: Oxford University Press, 2012.

TORRA, Karles. “Granollers i la febre del jazz". Ponències. Anuari del Centre d'Estudios de Granollers, n. 14, 2010, pp. 47-65. Consultado en https://docplayer.es/92632200-Granollers-ila-febre-del-jazz.html. Fecha de consulta: 08/11/2020.

\section{2. Catálogos de discos}


ARÉVALO MOLINA, Julio (responsable del catálogo). "Catálogo de discos de pizarra de la Biblioteca General de Ciudad Real”. En Alía Miranda, Francisco (coord.), La música en la Radio. Radio Ciudad Real EAJ 65 y sus discos de pizarra. Cuenca: Ediciones de la Universidad de Castilla-La Mancha, 2000.

Catálogo general de Discos Columbia. San Sebastián: Fábrica de Discos Columbia, 1942. Consultado en https://www.eresbil.eus/web/uploads/archivosGeneradorWeb/Catalogos/erelib_NL0214COL_ 01_v.pdf. Fecha de consulta: 06/11/2020.

Odeón, octubre de 1934. Consultado en https://www.eresbil.eus/web/uploads/archivosGeneradorWeb/Catalogos/erelib_A5-3K088_01_v.pdf. Fecha de consulta: 06/11/2020.

\section{3. Documentación de archivos}

[Acuse de recibo de oficio secreto]. A. Generales, 26 de marzo de 1943. AGA (3)49.1 21/00701.

Carta de G. Arias Salgado, 3 de noviembre de 1943. AGA (3)60 21/00781.

Carta dirigida al Bazar Álvarez, 20 de mayo de 1937. AGA (3)60 21/01359.

Circular 52. Instrucciones a los directores de emisoras de radiodifusión sobre la confección de programas, 8 de agosto de 1937. AGA (3)49.1 21/01455.

Circular 83. Historial de las Emisoras, 16 de marzo de 1942. AGA (3)49.1 21/00805.

Circular 95. Normas Sobre Censura Radiofónica, 17 de septiembre de 1942. AGA (3)49.1 21/00701.

Circular 96. [Celebración del $1^{\circ}$ de Octubre, día del Caudillo], 22 de septiembre de 1942. AGA (3)49.1 21/00806.

Circular 103. Día 29 de octubre, 16 de octubre de 1942. AGA (3)49.1 21/00806.

CONTRERAS, Federico, “Temas Musicales”. En [Cuaderno de emisiones de] Radio Madrid, 9 de septiembre de 1942. AGA (3)48 21/00012.

[Cuaderno de emisiones de] Radio Barcelona, 1 de enero de 1944. Consultado en https://ddd.uab.cat/pub/guiradbcn/1944/guiradben_a1944m1d1.pdf. Fecha de consulta: 06/11/2020.

[Cuaderno de emisiones de] Radio Barcelona, 3 de enero de 1943. Consultado en https://ddd.uab.cat/pub/guiradbcn/1943/guiradben_a1943m1d3.pdf. Fecha de consulta: 06/11/2020.

[Cuaderno de emisiones de] Radio Barcelona, 3 de diciembre de 1942. Consultado en https://ddd.uab.cat/pub/guiradbcn/1942/guiradbcn_a1942m12d3.pdf. Fecha de consulta: 06/11/2020. 
[Cuaderno de emisiones de] Radio Barcelona, 15 de octubre de 1943. Consultado en https://ddd.uab.cat/pub/guiradbcn/1943/guiradbcn_a1943m10d15.pdf. Fecha de consulta: 06/11/2020.

[Cuaderno de emisiones de] Radio Barcelona, 16 de diciembre de 1942. Consultado en https://ddd.uab.cat/pub/guiradbcn/1942/guiradbcn_a1942m12d16.pdf. Fecha de consulta: 06/11/2020.

[Cuaderno de emisiones de] Radio Barcelona, 21 de abril de 1944. Consultado en https://ddd.uab.cat/pub/guiradbcn/1944/guiradbcn_a1944m4d21.pdf. Fecha de consulta: 06/11/2020.

[Cuaderno de emisiones de] Radio Barcelona, 23 de octubre de 1942. Consultado en https://ddd.uab.cat/pub/guiradbcn/1942/guiradbcn_a1942m10d23.pdf. Fecha de consulta: 06/11/2020.

[Cuaderno de emisiones de] Radio Barcelona, 27 de octubre de 1942. Consultado en https://ddd.uab.cat/pub/guiradbcn/1942/guiradbcn_a1942m10d27.pdf. Fecha de consulta: 06/11/2020.

[Cuaderno de emisiones de] Radio Barcelona, 28 de enero de 1944. Consultado en https://ddd.uab.cat/pub/guiradbcn/1944/guiradbcn_a1944m1d28.pdf. Fecha de consulta: 06/11/2020.

[Cuaderno de emisiones de] Radio Barcelona, 30 de diciembre de 1943. Consultado en https://ddd.uab.cat/pub/guiradbcn/1943/guiradbcn_a1943m12d30.pdf. Fecha de consulta: 06/11/2020.

[Cuaderno de emisiones de] Radio España Bilbao, 19 de enero de 1943. AGA (3)48 21/00019.

[Cuaderno de emisiones de] Radio Madrid, 4 de octubre de 1943. AGA (3)48 21/00227.

Delegación Provincial de Educación Popular de Orense. Informe semanal de propaganda correspondiente a la segunda semana del mes de noviembre, 1942 [año tomado del oficio que presenta al informe]. AGA (3)48 21/00120. También en AGA (3)49.1 21/01532.

Delegación Provincial de Educación Popular de Orense. Informe semanal de propaganda correspondiente a la última semana del mes de noviembre, 1942 [año tomado del oficio que presenta al informe]. AGA (3)48 21/00120.

Delegación Provincial de Murcia. Informe periódico de las actividades propagandísticas, primera semana del mes de diciembre de 1942. AGA (3)48 21/00120. También en AGA (3) $49.121 / 01532$.

[Delegación Provincial de Murcia. Informe semanal, 14-20 Dbre (entendemos "del 14 al 20 de diciembre de 1942”)]. AGA (3)49.1 21/01532. 
"El futuro del Arte alemán. De los festejos en Munich". El Observador del Reich, n. 41, 20 de julio de 1937. AGA (9)17.12 51-21105.

LAGUNA AZORÍN, Emilio, "La crisis de nuestros músicos". En [Cuaderno de emisiones de] Radio Zaragoza, 22 de noviembre de 1943. AGA (3)48 21/00260.

LLABRÉS, Pedro. “Eutrapelias Radiofónicas”. En [Cuaderno de emisiones de] Radio España, 20 de septiembre de 1942. AGA (3)48 21/00007.

Nota de servicio interior. De Jefe de Sección de Asuntos Generales de Propaganda a Jefe de Sección de Propaganda Oral, 19 de septiembre de 1942. AGA (3)49.1 21/00118.

Nota de servicio interior. De Jefe de Sección de Asuntos Generales de Propaganda a Jefe de Sección de Propaganda Oral y Educación Musical, 8 de octubre de 1942. AGA (3)49.1 21/00118.

Nota dirigida al Bazar Electra, 20 de mayo de 1937. AGA (3)60 21/01359.

Oficio de la Delegación Nacional de Propaganda. P. O. Sección Musical, 21 de mayo de 1942. AGA (3)49.1 21/00102.

Oficio de la Delegación Nacional de Propaganda. P. Oral y E. Musical, 2 de octubre de 1942a. AGA (3)49.1 21/00118.

Oficio de la Delegación Nacional de Propaganda. P. Oral y E. Musical, 2 de octubre de 1942b. AGA (3)49.1 21/01533.

Oficio de la Delegación Nacional de Propaganda. P. Oral y E. Musical, 23 de septiembre de 1942. AGA (3)49.1 21/00118.

Oficio de la Delegación Nacional de Propaganda. P. Oral y E. Musical, 31 de octubre de 1942. AGA (3)49.1 21/00118.

Oficio de la Delegación Provincial de Cuenca a la Sección de Propaganda Oral, 25 de septiembre de 1942. AGA (3)49.1 21/00118.

Oficio de la Delegación Provincial de Guipúzcoa a Propaganda Oral, 20 de octubre de 1942. AGA (3)49.1 21/00118.

Oficio secreto. Secretaría, 22 de marzo de 1943. AGA (3)49.1 21/00701.

PRADOS LÓPEZ, José. "Crítica de Arte [galerada intervenida]”. En Radio España Madrid, 21 de septiembre de 1942. AGA (3)48 21/00331.

PULIDO, Delfín, “Ayer y Hoy en el Concepto de la Música”. En [Cuaderno de emisiones de] Radio Madrid, 30 de agosto de 1942. AGA (3)48 21/00012.

SANZ, Maximiliano, "La Prensa en la Radio". En [Cuaderno de Emisiones de] Radio SEU, 21 de marzo de 1944. AGA (3)48 21/00242.

\section{4. Hemeroteca y otras publicaciones periódicas}


CIFRA, "No podrá interpretarse música clásica adaptada al jazz". PROA. Diario de Falange Española Tradicionalista y de las J.O.N.S., 3 de septiembre de 1942.

DE CALATRAVA, Honorato, "Ruido y Música". Lanza, n. 307, 11 de mayo de 1944. "El Sindicato Nacional del Espectáculo y sus recientes disposiciones". Ritmo, n. 159, octubre de 1942.

"Grupo de Música. Actividades de este Grupo durante el pasado mes de agosto". Boletín del Sindicato Nacional del Espectáculo, n. 5, agosto de 1942.

"Nota del Sindicato Nacional del Espectáculo". La Vanguardia Española, 1 de octubre de 1942. Consultado en: http://hemerotecapaginas.lavanguardia.com/LVE07/HEM/1942/10/01/LVG19421001-006.pdf. Fecha de consulta: 29/07/2020

RAMOS ECHAPARE, Miguel. "El «jazz» y la música «clásica»”. POM (Profesores de Orquesta y Música de Madrid), n. 10, julio de 1936. Consultado en http://hemerotecadigital.bne.es/issue.vm?id=0003840478\&page $=13 \&$ search $=$ jazz + musica + cla sica\&lang=es. Fecha de consulta: 29/07/2020

"Sindicato Local del Espectáculo: Sección Músicos Importante Aviso". Falange, 22 de septiembre de 1942.

TERCERO, Manuel. "La Música Negroide y la Cultura Europea”. ABC, 10 de octubre de 1942. Consultado en

http://hemeroteca.abc.es/nav/Navigate.exe/hemeroteca/madrid/abc/1942/10/10/026.html. Fecha de consulta: 06/11/2020.

VALCÁRCEL, Juan. “El jazz y la música clásica”. POM (Profesores de Orquesta y Música de Madrid), n. 3, diciembre de 1935a. Consultado en http://hemerotecadigital.bne.es/issue.vm?id=0003839220\&page $=16 \&$ search $=$ juan+valc\%C3 \%A1rcel+jazz\&lang=es. Fecha de consulta: 06/11/2020.

VALCÁRCEL, Juan. “Jazz”. POM (Profesores de Orquesta y Música de Madrid), n. 2, noviembre de 1935 b. Consultado en http://hemerotecadigital.bne.es/issue.vm?id=0003839098\&page $=12 \&$ search $=$ juan + valc\%C3 \%A1rcel+jazz\&lang=es. Fecha de consulta: 06/11/2020.

"Valencia. Parte de actividades núm. 23, mes de septiembre de 1942. Grupo Música". Boletín del Sindicato Nacional del Espectáculo, n. 6, septiembre de 1942.

"Valladolid. Informe mensual de las actividades del Sindicato local de Espectáculos públicos de Valladolid. Grupo de Música”. Boletín del Sindicato Nacional del Espectáculo, n. 6, septiembre de 1942 .

"Velando por la pureza de la música". La Vanguardia Española, 3 de septiembre de 1942. Consultado en: http://hemerotecapaginas.lavanguardia.com/LVE07/HEM/1942/09/03/LVG19420903-005.pdf. Fecha de consulta: 29/07/2020. 


\section{5. Normativa}

"Decreto de 4 de agosto de 1944 determinando las funciones que corresponden a la Vicesecretaría de Educación Popular en orden a los Servicios de Radiodifusión”. Boletín Oficial del Estado, n. 222, 9 de agosto de 1944. Consultado en https://www.boe.es/datos/pdfs/BOE//1944/222/A0605706058.pdf. Fecha de consulta: 10/11/2020.

"Decreto de 19 de febrero de 1942 por el que se reconoce al Sindicato Nacional del Espectáculo como corporación de Derecho público", Boletín Oficial del Estado, n. 66, 7 de marzo de 1942. Consultado en https://www.boe.es/datos/pdfs/BOE//1942/066/A01659-01660.pdf. Fecha de consulta: $10 / 11 / 2020$.

“Grupo de Música. Orden”, Boletín del Sindicato Nacional del Espectáculo, n. 5, agosto de 1942.

"Ley de Bases de la Organización Sindical de 6 de diciembre de 1940". Boletín Ofícial del Estado, n. 342, 7 de diciembre de 1940. Consultado en https://www.boe.es/datos/pdfs/BOE//1940/342/A08388-08392.pdf. Fecha de consulta: $10 / 11 / 2020$.

"Ley [de organización de la Administración Central del Estado]". Boletín Oficial del Estado, n. 467, 31 de enero de 1938. Consultado en https://www.boe.es/datos/pdfs/BOE//1938/467/A0551405515.pdf. Fecha de consulta: 10/11/2020.

"Ley de 23 de junio de 1941 sobre clasificación de Sindicatos", Boletín Oficial del Estado, n. 192, 11 de julio de 1941. Consultado en https://www.boe.es/datos/pdfs/BOE//1941/192/A0519105192.pdf. Fecha de consulta: 10/11/2020.

"Ley de 26 de enero de 1940 sobre Unidad sindical", Boletín Oficial del Estado, n. 31, 31 de enero de 1940. Consultado en https://www.boe.es/datos/pdfs/BOE//1940/031/A00772-00773.pdf. Fecha de consulta: 10/11/2020.

\section{6. Partitura}

Othmar Klose u. Rudi Lukesch. "Hör' mein Lied, Violetta! Italienische Tangoserenade. Mit Verwendung eines Motiva aus «Traviata» von Giuseppe Verdi”. S. d. Partitura. Consultada en https://www.musicalion.com/es/scores/partituras-shop/135994/klose-othmar-lukesch-rudolfh\%C3\%B6r-mein-lied-violetta. Fecha de consulta: 06/11/2020.

\section{7. Referencias sonoras}

Benny Goodman. "Sing, Sing, Sing (With A Swing)". Live at Carnegie Hall. Holland: CBS, s. d. LP.

Bonet de S. Pedro y los 7 de Palma. "Raska-yu”. S. 1.: Regal, s. d. 78 rpm. BU.UCLM. Disco 2559. Ref. 3218.

Bonet de San Pedro y los Siete de Palma, "Raska-yu”. Barcelona: Compañía del Gramófono Odeón, 1943. 78 rpm. BNE/Ds/97/16.

Claude Debussy. "Clair de lune =Moonlight : no. 3 from Suite Bergamasque". New Jersey: RCA Victor Division of Radio Corporation of America, 1942. 78 rpm. BNE/DS/10632/8. 
Emilio Goya con Tejada y su Gran Orquesta. "Oye mi canción Violeta”. S. 1.: Columbia, s. d. 78 rpm. BU.UCLM. Disco 1.970. Ref. 2674.

Glenn Miller. "Moonlight serenade”. England: Regal Zonophone, 1941?. 78 rpm. BNE/DS/15517/8.

Gota Ljumberg y Walter Widdop con acompañamiento de orquesta. "La Walquiria/Dúo de amor: I parte, II parte”. Barcelona: Compañía del Gramófono, 1930. 78 rpm.

BNE/DS/10567/5.

Heric Harden. "Guerra de Valses/Potpourri marcha sobre motivos de Johann Strauss". Barcelona: Compañía Gramófono Odeón, 1934 (fecha establecida según el Catálogo Odeón citado en este trabajo). $78 \mathrm{rpm}$. Colección privada.

José Azarola. "Fantasías, $1^{\text {a }}$ parte: a tiempo de fox/Fantasías, $2^{\mathrm{a}}$ parte: a tiempo de fox". Barcelona: Compañía del Gramófono Odeón, 1942.78 rpm. BNE/ Ds/57/10.

Orquesta Benny Goodman. "Bach va a la ciudad/Farewell Blues". Barcelona: Compañía del Gramófono Odeón, 1942. 78 rpm. BNE/Ds/76/5.

Orquesta Gran Casino. "Farándola”. Barcelona: Compañía del Gramófono Odeón, 1942. 78 rpm. BNE/Ds/57/12.

Orquesta Martín de la Rosa. "Violeta". Barcelona: Compañía del Gramófono Odeón, 1940. 78 rpm. BNE/Ds/48/3.

Orquesta Nat Gonella. "Tocando el arpa dorada”. Barcelona: Compañía del Gramófono Odeón, 1943. 78 rpm. BNE/Ds/99/16.

Orquesta New Myfair. "Popurrí de one-steps/Popurrí de valses antiguos". Barcelona: Compañía del Gramófono Odeón, 1942. 78 rpm. BNE/Ds/77/4.

Orquesta Plantación. "Mi único romance”. Barcelona: Compañía del Gramófono Odeón, 1942. 78 rpm. BNE/Ds/79/16.

Rafael Medina, con acompañamiento de la Orquesta Martín de la Rosa. "Tristeza". Barcelona: Compañía del Gramófono Odeón, 1940. 78 rpm. BNE/Ds/17/15.

Rafael Medina y su Orquesta. "Ilusión/Mi última romanza”. Barcelona: Compañía del Gramófono Odeón, 1942. 78 rpm. BNE/Ds/66/14.

Tejada y su Gran Orquesta. "Nocturno”. San Sebastián: Fábrica de Discos Columbia, 1939? $78 \mathrm{rpm}$. BNE/DS/14550/12. 